\title{
On the use of satellite remote sensing to detect floods and droughts at large scales.
}

Lopez. $T^{1,2}$, Al Bitar A. ${ }^{3}$, Biancamaria S. ${ }^{4}$, Güntner A. ${ }^{5,6}$, Jäggi A. ${ }^{7}$

1. Institut de Recherche Technologique (IRT) Saint-Exupéry, Géoscience Environnement Toulouse (GET), 14 avenue Edouard Belin, 31400 Toulouse, France, lopez.teodolina@gmail.com, ORCID: 0000-0001-8550-7270*

2. International Space Science Institute (ISSI), Hallerstrasse 6, 3012 Bern, Switzerland

3. CESBIO, CNES, CNRS, IRD, Université Paul Sabatier, 13 avenue du Colonel Roche, 31400 Toulouse, France, ahmad.albitar@cesbio.cnes.fr

4. LEGOS, CNES, CNRS, IRD, Université Paul Sabatier, 18 avenue Edouard Belin, Toulouse, France, sylvain.biancamaria@legos.obs-mip.fr

5. Helmholtz Centre Potsdam GFZ German Research Centre for Geosciences, Telegrafenberg, 14473 Potsdam, Germany, andreas.guentner@gfz-potsdam.de

6. University of Potsdam, Institute of Environmental Science and Geography, 14476 Potsdam, Germany

7. Astronomical Institute, University of Bern, Sidlerstrasse 5, 3012 Bern, Switzerland, adrian.jaeggi@aiub.unibe.ch

\section{Article Highlights}

- Each components of the terrestrial water storage is a key hydrological variable to understand floods and drought periods.

- Their monitoring at river basin scale and over long period of time is facilitated by large scale sensors.

- The combination of Earth observations with other datasets can be an asset for the prediction of hydrological events and for monitoring.

\section{Keywords:}

Floods, droughts, large-scale, Terrestrial Water Storage, GRACE, SMOS, satellite altimetry, SWOT.

Received: 23 March 2020 / Accepted: 10 September 2020

DOI : $10.1007 / \mathrm{s} 10712-020-09618-0$

\begin{abstract}
Hydrological extremes, in particular floods and droughts, impact all regions across planet Earth. They are mainly controlled by the temporal evolution of key hydrological variables like precipitation, evaporation, soil moisture, groundwater storage, surface water storage and discharge. Precise knowledge of the spatial and temporal evolution of these variables at the scale of river basins is essential to better understand and forecast floods and droughts. In this article we present recent advances on the capability of Earth Observation (EO) satellites to provide global monitoring of floods and droughts. The local scale monitoring of these events which is traditionally done using high resolution optical or SAR (Synthetic Aperture Radar) EO and in situ data will not be addressed. We discuss the applications of moderate to low spatial resolution space-based observations, e.g. satellite gravimetry (GRACE and GRACE-FO), passive microwaves (i.e. SMOS) and satellite altimetry (i.e. the JASON series and the Copernicus Sentinel missions) with supporting examples. We examine the benefits and drawbacks of integrating these EO datasets to better monitor and understand the processes at work and eventually to help in early warning and management of flood and drought events. Their main advantage is their large monitoring

*Present address
\end{abstract}


scale that provides a "big picture" or synoptic view of the event that cannot be achieved with often sparse in situ measurements. Finally, we present upcoming and future EO missions related to this topic including the SWOT mission.

\section{Introduction}

Hydro-meteorological extreme events count among the costliest natural disasters affecting human societies. They produce the largest cumulative total of life lost and socio-economical costs. In the context of global warming, these extreme events are intensifying and becoming more frequent in recent years (Stocker et al. 2013; Yamazaki et al. 2018 and references therein). This review paper focuses on floods and droughts and is part of a special issue on the benefits of integrating spaced-based or air-borne observations in order to better predict, monitor and help in post-disaster management of natural hazards in which several themes as storm surges (Melet et al. 2020), tsunamis (Hébert et al. 2020), landslides (Lissak et al. 2020) and fire (Pettinari and Chuvieco 2020) are investigated. Space-based or air-borne Earth Observations (EOs) have several benefits: 1) their instruments are not affected by the events, 2) they collect consistent data at different wavelengths and over different spatio-temporal scales and 3) they cover dangerous/inaccessible areas. Overall, EO data allow better understanding of the relationship between the hydrosphere, atmosphere, biosphere and solid Earth, and provide a global view of the phenomena and are complementary to in situ measurements (Tralli et al. 2005; Petiteville et al. 2015). Moreover, EO data can be used synergistically with demographic and socio-economic data to understand how hazards impact human societies, enhance our knowledge of the human influence on risks and thus elaborate mitigation, disaster and post-disaster management (Tralli et al. 2005).

In this article, the focus is put on recent advances on the monitoring of floods and droughts at the scale of large river basins through the observation of specific components of the hydrological cycle via space based EO. At the end of last century, droughts counted for one-fifth of the damage caused by natural hazards and has steadily increased in recent decades. On the other hand, the cost of floods is expected to increase by ten folds in 2030 (World Resources Institute 2019). It is important to note that this article does not address the local scale monitoring of these events which is traditionally done using high resolution optical or SAR (Synthetic Aperture Radar) EO (e.g. Domeneghetti et al. 2019) and in situ data. We review the innovative applications on the use of moderate to low spatial resolution missions to provide information facilitating the understanding and thus the forecasting of floods and droughts and discuss the future of these Earth Observation data. 


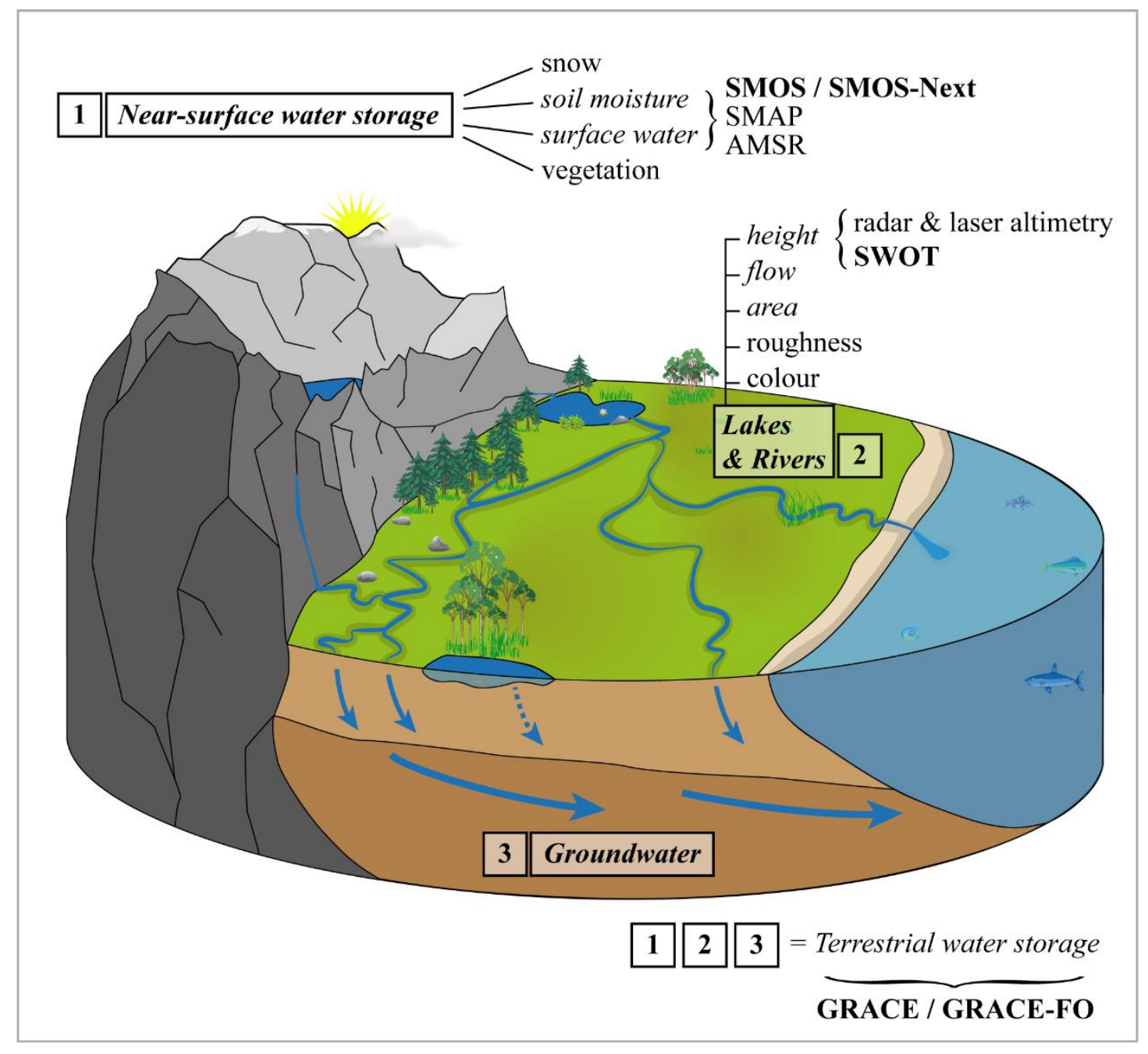

Fig 1 Sketch of the different water storage compartments investigated in this study. Terms in italic are state variables considered and bold terms are satellite missions presented in this article.

\section{Water Storage on the Continents: General Remarks}

Freshwater represents less than $3 \%$ of the total amount of water on Earth. On land, freshwater is stored in various reservoirs such as ice caps, snow, glaciers, groundwater, soil moisture (in the unsaturated soil and root zone, i.e., in the upper few meters of the soil (e.g. Hillel 1998)) and in surface water bodies (rivers, lakes, man-made reservoirs, wetlands and inundated areas) (Fig 1). These different storage compartments are in direct interactions with the atmosphere. For example, in the tropical Pacific, longterm droughts and floods are under the influence of the El Niño-Southern Oscillation (ENSO) events (e.g. Ward et al. 2014; Fok et al. 2018 and references therein).

Short-time hydrological events such as droughts and floods (i.e., events of water surplus or deficit that deviate from the average conditions over days to several months) are controlled by natural phenomena and anthropogenic activities. Key hydrological variables that drive and characterize these events are precipitation, soil moisture, groundwater storage and river discharge (e.g. Niu et al. 2014). Precipitation is considered as the main variable for the assessment of meteorological droughts and it is the main driver of flood events and thus the main input for hydrological flood models. The World Meteorological Organization (WMO) recommends the use of the Standardized Precipitation Index (SPI) for the assessment of wet and dry conditions (Svoboda et al. 2012). While its importance is not debated, complementary indices have emerged in the recent decades for characterizing of droughts and floods at large-scale. Here we address the monitoring of flood and drought events in terms of soil moisture, inundated areas, groundwater, total water storage change and river discharge. Soil moisture is a key 
variable of the water cycle that links subsurface and surface to atmospheric processes (e.g. Robinson et al. 2008; Niu et al. 2014; Grillakis et al. 2016; Babaeian et al. 2019). It is identified as an Essential Climate Variable (ECV) by the Global Climate Observing System (GCOS) (Bojinski et al. 2014) and is a major part of the so called "Green Water" (Hoekstra et al. 2011). As stated by Babaeian et al. (2019) "soil moisture is an effective indicator for drought conditions and flood risks and thus plays a unique role in their prediction". In fact, soil moisture availability in the root zone is a direct indicator for agricultural droughts and can also inform on the wetness status in advance of strong rainfall events as an indicator of possible flood generation. Soil moisture accounts for about $0.79 \%$ of the available freshwater on Earth but it is the main interface for the atmosphere / biosphere / subsurface interactions.

Open water bodies include lakes, rivers, wetlands, peatland, floodplains and man-made reservoirs. Wetlands cover about 4\% of the Earth's land surface (Pekel et al. 2016) and are mostly present in tropical areas; for example, up to $20 \%$ of the Amazon Basin (Parrens et al. 2017). They play an important role in the hydrological regimes of large river basins as transition zones. Wetlands and floodplains are also the place of ecosystems with rich biodiversity (Costa et al. 2013) but they are very vulnerable to extreme changes.

Rivers account for $0.015 \%$ of the available freshwater globally, but like soil moisture they are the transfer medium for a large amount of the available freshwater. Since more than $50 \%$ of the world's population lives closer than $3 \mathrm{~km}$ to a surface freshwater body, and in majority near small to large rivers (74\%) (Kummu et al. 2011), most of the world population is impacted by hydrological droughts and floods.

Groundwater is the main reservoir of available freshwater globally (96.7\%) and accounts for $80 \%$ of the water extracted by humans. Groundwater is becoming an important supply of freshwater ( $\sim 50 \%$ of the drinking water) (Foster and Loucks 2006) in different regions of the world as the surface water is becoming less reliable (e.g. Richey et al. 2015). Arid and semi-arid regions represent $\sim 30 \%$ of the Earth's surface and groundwater constitutes a significant resource of freshwater in these areas; poorly renewable as the water input is often very localised but exploitable (e.g. Margat and Van der Gun 2013). The importance of groundwater supply is known in drought conditions but only few EO-based studies have addressed its contribution to flood events. In karstic regions, groundwaters directly contribute to the generation of floods. However, they remain less common than river flooding and generate less damages (e.g. Yu et al. 2019). Runoff from groundwater storage tends to be delayed relative to the faster reacting near-surface storage compartments ( $\mathrm{Yu}$ et al. 2019 and references therein)and can thus have a major contribution to the later stages of a flood event (Huntingford et al. 2014).

Precise knowledge of the spatial and temporal evolution of the aforementioned storage variables and of their sum as an integrative measure of the water storage in a river basin, i.e., total terrestrial water storage (TWS) change which is one of the four fundamental components of the terrestrial water balance besides precipitation, evapotranspiration and runoff, are important to better understand and forecast flood and drought events at the scale of river basins.

\section{Space-Based Observations of the Water Cycle Components}

\subsection{Monitoring of Soil Moisture}

The observation of surface soil moisture can be obtained using active or passive microwaves (Njoku et al. 2003; Kerr et al. 2012; Tomer et al. 2015). Optical remote sensing on the other hand will provide a proxy information of the impact of soil moisture on soil emissivity and is more applied for soil texture characterisation (Gomez et al. 2019). The retrieval of soil moisture from active microwave is generally applied using SAR data from ASCAT (Wagner et al. 2013), RadarSat (Tomer et al. 2015) or Sentinel-1 (Paloscia et al. 2013). The retrieval of soil moisture from passive microwave has been applied to CBand (Njoku et al. 2003) and L-Band (Entekhabi et al. 2010; Kerr et al. 2012). The more recent L-band data from the SMOS (ESA) and SMAP (NASA) missions are considered as the most adapted for soil moisture retrieval considering radiative transfer physics (Ulaby 1981), but they can be hampered by 
their coarse resolution ( $\sim 50 \mathrm{~km}$ and $36 \mathrm{~km}$, respectively). Downscaling algorithms combining the microwave to optical or radar have been applied to enhance the resolution (Merlin et al. 2010; Tomer et al. 2016). The computation of root zone soil moisture from surface soil moisture can be provided through parsimonious models (Albergel et al. 2008; Al Bitar et al. 2013) or assimilation into land surface models (LSM) (Reichle 2018). The advantage of the parsimonious models is their ability to reduce the number of inputs mainly due to their independence from precipitation data. This is a major advantage in large irrigated areas. The advantage of data assimilation (DA) systems is their coherent retrieval or prediction of the ensemble of state variables (e.g. root zone soil moisture, surface and/or vegetation temperatures), still one must keep in mind that errors on one variable will impact the other ones. Nevertheless, SMOS and SMAP missions provide a high temporal revisit (3 days for ascending and descending orbits). They give access to consistent information over the globe as the acquisition configuration are similar across ecosystems. Yet several drawbacks can be mentioned as 1) the sensitivity of L-Band acquisition to radio frequency interference from illegal emissions in the observation bandwidth from civil and military applications, 2) the retrieval using parsimonious models requires one to take into consideration the transpiration of the vegetation that is ill characterised and, in many cases, bypassed and 3) the resolution of the original data often needs to be enhanced using error-prone disaggregation approaches.

\subsection{Monitoring Inundated Areas Using Passive Microwaves}

Flooded areas are commonly monitored using high resolution thermal, visible or radar observations, as they can provide information at local scale. For example, Pekel et al. (2016) provided a 30 years database of surface water changes from LANDSAT (NASA) dataset. Mueller et al. (2016) presented a similar analysis over the Australian continent while providing the details for an operational continental water detection suite. These three techniques present major drawbacks in specific conditions. For optical (thermal and visible) remote sensing the cloud cover can be a major issue during flood events and over tropical areas. Moreover, thermal remote sensing is highly sensible to the presence of water vapor in the atmosphere while relative humidity over $80 \%$ are frequent in tropical regions and during wet weather. SAR is widely used to monitor the flood extents (Bonn and Dixon 2005; Matgen et al. 2011; Twele et al. 2016) and is an essential data source used during the activation of the International Disasters Charter. The main drawbacks of the SAR data are the impact of dense vegetation and soil roughness in dry conditions. In this paper we are addressing the monitoring of inundated areas at the scale of river basins. In these conditions the use of passive microwaves has been demonstrated in several studies (Prigent et al. 2007; Schroeder et al. 2015; Al Bitar et al. 2016).

Recently, the multi-angular full-polarizations brightness temperatures from SMOS (Al Bitar et al. 2017) were used in a contextual approach to retrieve the flooded water fractions at $25 \mathrm{~km}$ resolution (Parrens et al. 2017). The application to the Amazonian basin shows that flood and drought events related to water surface changes can be monitored at 10 days temporal resolution. To reduce the inconvenience of coarse resolution, disaggregation algorithms to sub-kilometric resolutions have been applied to such datasets using auxiliary data related to flood probabilities, Digital Elevation Models (DEM), and basin hydro-morphological information (Aires et al. 2017; Parrens et al. 2019). At these resolutions the dataset is highly dependent on the input auxiliary data quality, mainly the DEM. The main advantage of microwave-based datasets is their ability to provide large-scale information. For example, the SMOS swath is about $1400 \mathrm{~km}$. Another advantage related to the large scale is the ability though the frequent revisits (3 days global coverage for ascending and descending orbits) to provide coherent and consistent information at global scale. Finally, the use of low-frequency passive acquisition (e.g. L-Band at 1.4 $\mathrm{GHz}$ ) is less prone to screening effect from the vegetation compared to passive C-Band (AMSR-E). Low-frequency passive sensors are also less sensitive to vegetation structure and surface roughness than in in active microwaves (ASCAT). Still the data have several drawbacks, e.g. 1) the low-resolution of the acquisition and 2) their strong vulnerability to Radio Frequency Interference (RFI) (Soldo et al. 2016) because of the swath width and the low measured surface emissions $\left(10^{-4} \mathrm{~W} \mathrm{~m}^{-2}\right)$. 


\subsection{River Elevation and Discharge}
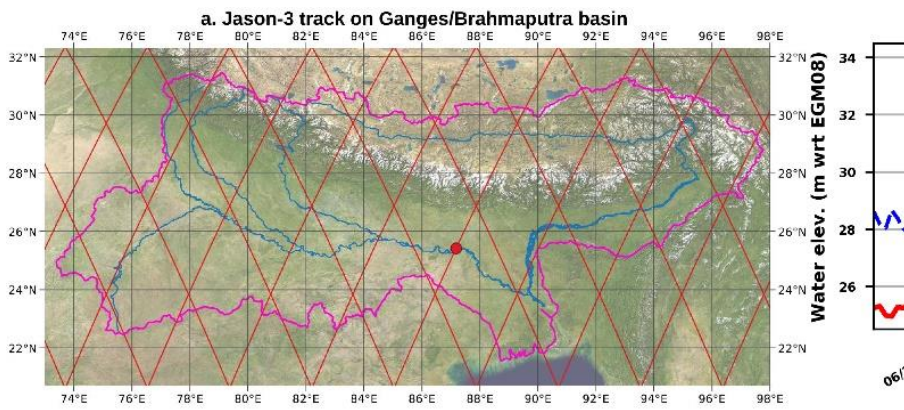

b. Koshi River (J3 track 155)

Fig 2 a Jason-3 satellite tracks (red lines) over the Ganges/Brahmaputra basin (magenta boundaries, which come from GRDC Major River Basins database). The background image comes from the NASA MODIS "Blue Marble Next Generation" image (Stöckli et al. 2005). Blue lines represent the Ganges river and its major tributaries, and the Brahmaputra river. $\boldsymbol{b}$ Jason-3 water elevation time series on the Koshi river (red dot on panel a.) and on a nearby lake connected to the river during seasonal floods (red and blue lines, respectively).

Nadir radar and SAR altimeters (e.g., Jason-1,2,3, Envisat, Saral/AltiKa and Sentinel-3A/B) provide measurement of water elevations (i.e. the distance between water body surface and a reference surface, ellipsoid or geoid). However, they cannot provide water depth, nor any information on water body bathymetry below the lowest water level observed. Initially conceived to measure ocean surface topography, they have been used since the 1990s to also measure inland waters elevations with an accuracy of few decimetres to a metre over continents (Santos da Silva et al. 2010), depending on the observation configuration, previous measurements and instrument characteristics. The main limitations of such instruments are their spatial and temporal sampling. They only provide measurements along the satellite track, missing all water bodies that are not overflown beneath by the satellite. Current missions on a repetitive orbit (the satellite passes over the same point at a constant time step) have an intertrack distance (i.e. the distance between two adjacent ascending or descending tracks) at the equator between $315 \mathrm{~km}$ (the Jason series) to $52 \mathrm{~km}$ (when considering the two satellites of the Sentinel-3 series). The lower the intertrack distance, the higher the repeat period. For example, the Jason satellites have a 10 days revisit time, whereas it is 27 days for the Sentinel-3 satellites. In contrast, in situ gauges provide daily or better time sampling. These characteristics restrict nadir altimeter observation capacity to large scale floods (Coe and Birkett 2004; Frappart et al. 2005; Biancamaria et al. 2011; Boergens et al. 2019). Nevertheless, satellite altimetry provides free measurements over multiple points of the river network (see Fig 2a for an example of Jason-3 space sampling over the Ganges/Brahmaputra basin). They have thus been quite useful for large and poorly gauged basins, especially in a context of transboundary basins, to provide measurements both on the river and on the floodplain (Fig $\mathbf{2 b}$ ).

To overcome the space and time sampling issue, many studies have combined observations from the same mission at different location along the river network or even multiple observations from different altimetry missions, in order to increase water level time series to observe as many events as possible (Hossain et al. 2014; Tourian et al. 2016; Boergens et al. 2019). For example, Tourian et al. (2017) has been able to compute daily water level and discharge on the Niger River mainstream using Envisat, SARAL/AltiKal and Jason-2 data and the few in situ data available for this basin.

Combining altimetry observations with measurements from other space sensors is also a promising perspective. Combination of altimetry data with optical sensors, especially the MODerate resolution Imaging Spectroradiometer (MODIS), has been the most investigated (Tarpanelli et al. 2015, 2017, 2019; Ovando et al. 2018; Pham et al. 2018). In these studies, relationships between MODIS images for different wavebands and altimetry-based water elevations are computed to complement altimetry time series with the high temporal resolution of optical sensors enabled by their large swaths. 


\subsection{Monitoring of Terrestrial Water Storage Including Groundwater}

In spite of its fundamental role for the global water cycle, for a long time there was no technique available that allowed for monitoring variations in total terrestrial water storage in an integrative way, including all relevant storage compartments on and below the Earth surface. Also, the lack of in situ data with the ability to measure long-term changes in the groundwater storage explains why the groundwater variability was poorly constrained (e.g. Famiglietti et al. 2011; Famiglietti 2014; Chen et al. 2016; Bonsor et al. 2018) before the launch of new types of sensors. Indeed, since the beginning of the century, a new generation of Low Earth Orbiter (LEO) satellites has been operated to precisely determine the Earth's static gravity field, such as the GOCE (Gravity field and steady-state Ocean Circulation Explorer) mission (Drinkwater et al. 2006). The most important one for hydrological applications is the Gravity Recovery and Climate Experiment (GRACE) mission (Tapley et al. 2004) and its successor GRACE-FO (Landerer et al. 2020), which is dedicated to map the static gravity field and its time variations. Since its launch in March 2002, with the co-orbiting twin vehicles, it has measured the time variations of the Earth's gravity field for 15 years and with unprecedented precision. These two satellites are in the same orbit at $450-500 \mathrm{~km}$ altitude with a separation of about $200 \mathrm{~km}$. The high-precision measurements of the inter-satellite distance change were enabled by the on-board KBand Range Rate (KBRR at a precision of $0.1 \mathrm{~m} \mathrm{~s}^{-1}$ ) system (Tapley et al. 2004). Together with Global Positioning System (GPS) observations and on-board accelerometer and star camera observations the estimation of the gravity variations is indirectly obtained by inverting the ultra-precise KBRR observations between the two vehicles (Houborg et al. 2012). GRACE and GRACE-FO yield crucial information on the temporal and spatial variations of TWS for the period 2002 to today, with a gap between GRACE and GRACE-FO from June 2017 to June 2018. TWS is a unique integrative observation that notably includes, e.g., groundwater storage variations down to any aquifer depth and the mass loss of ice caps and glaciers, typically with a temporal resolution of one month and spatial resolution of $\sim 300 \mathrm{~km}$. From the TWS variations, water storage variations in individual storage compartments such as groundwater can be singled out by the subtraction of water mass variations in other components if available from complementary observations and models or in a model-based data assimilation framework (see, e.g. Frappart and Ramillien 2018). Both approaches are at the expense of additional errors introduced in the final product by the uncertainties of the separation approaches themselves.

\section{Progress in Flood Applications}

Flood is defined by the World Meteorological Organization International Glossary of Hydrology (WMO 2012) as: "(1) Rise, usually brief, in the water level of a stream or water body to a peak from which the water level recedes at a slower rate. (2) Relatively high flow as measured by stage height or discharge." In this review study, we focus on long-lasting floods with large coverage in space which can be captured by moderate- to low- spatial resolution space-based observations. We do not consider flash floods (defined as "flood of short duration with a relatively high peak discharge" in WMO, (2012)) which can last a few hours and be very intense locally and cannot be observed with such satellite instruments. The following sections present how the space-based observations presented in section 3 can observe and provide meaningful measurements for these large-scale floods.

\subsection{Added Value of Satellite Altimetry}

Daily discharge has been computed using DA techniques by updating hydraulic/hydrological model state variables with altimetry-derived observations (Schumann et al. 2010; Hirpa et al. 2013; Michailovsky et al. 2013; Finsen et al. 2014; Emery et al. 2018). These improved time series help to get better estimates of the dynamics and the magnitude of flood events at the river basin scale. A particular advantage compared to classical approaches based on often scarce in situ data is that the altimetry-based reanalyses may allow for a spatially distributed discharge estimation for large basins. In a few studies, the calibration of hydraulic model parameters with altimetry time series has been investigated (e.g. 
Schneider et al. 2017; Jiang et al. 2019). As highlighted by Jiang et al. (2019), for parameter estimation, contrarily to water elevation/discharge time series densification by higher temporal resolution, a better spatial coverage is more important than re-visit times with high frequency. The benefit of a better calibrated model is the possibility to simulate more accurately past events and to eventually forecast them with lower uncertainty in future. Bates et al. (2014) provides a more in-depth review of satellite data used to observe floods and how they have been combined with models.

However, very few studies implemented a proof-of-concept of flood forecasting system using altimetry observations. Based on the work from Biancamaria et al. (2011), Hossain et al. (2014) implemented a real flood forecasting system of daily water levels with a 5-day lead time over Bangladesh (Ganges/Brahmaputra/Meghna basin) using Jason-2 data and a hydraulic model. This system has then been used operationally by Bangladesh Institute of Water Modeling as a decision-making tool (Hossain et al. 2014b). Tarpanelli et al. (2017) also developed two proof-of-concept systems to forecast discharge with a 4-day lead time over the Niger basin, using either MODIS images, or altimetry data. They found that altimetry data provide more accurate forecasts but lack sufficiently frequent re-visit times. On the contrary, the MODIS-based forecast system is somewhat less accurate but enables daily forecasts which are more suitable for operational agencies. However, to the authors' knowledge, this system has not yet been used operationally.

One must keep in mind that nadir radar altimeters due to the vertical accuracy, and time and space samplings cannot bring as much information as in situ data. However, due to their large spatial coverage, especially for big transboundary basins and where there are few gauges or where the gauge data are not shared with downstream countries, altimetry measurements could help to provide more knowledge on large floods.

\subsection{Monitoring and Predicting Flood Events With Satellite Gravimetry}

The mass changes observed by GRACE and GRACE-FO encompass water storage changes associated with the evolution of hydrological events. Satellite gravimetry thus can be used to assess the magnitude of large-scale flood events in terms of their storage amplitude, duration and frequency in river basins worldwide. Furthermore, monitoring catchment wetness conditions opens up the opportunity to use GRACE / GRACE-FO in a predictive mode for early warning applications, i.e., for indicating river basin states that favour the generation of flood events. Added value for flood monitoring and forecasting relative to other observation data can be expected as gravimetry is the only comprehensive observation technique that delivers the wetness state in an integrated form for all TWS compartments.

\subsubsection{Monitoring Flood Events With GRACE / GRACE-FO}

Monthly GRACE products from various processing centres and with different solution strategies (see, e.g. Jean et al. 2018 for an overview of available solutions) have frequently been used to describe flood events. For example, Seitz et al. (2008) reported evidence of observed extreme weather fluctuations in Central Europe for the period 2003-2008 including the associated flood events by performing a regional analysis of GRACE data over Europe based on spherical wavelet / B-spline and global spherical harmonic solutions. Chen et al. (2010) studied the exceptional 2009 Amazon flood and inter-annual terrestrial water storage change observed by GRACE and concluded that the TWS increase in the lower Amazon basin in the first half of 2009 were clearly associated with the exceptional flood season in that region.

Abelen et al. (2015) related soil moisture from the WaterGAP Global Hydrology Model (WGHM) (Döll et al. 2003) and from the satellite sensors Advanced Microwave Scanning Radiometer-Earth Observing System (AMSR-E) and Advanced Scatterometer (ASCAT) to GRACE-based total water storage variations. For the La Plata basin in South America, they found that GRACE water storage dynamics represented the ENSO-dependent sequence of drought and flood events with a temporal delay of few months compared to near-surface soil moisture. Furthermore, Boening et al. (2012) and Fasullo et al. (2013) reported heavy precipitation over the Australian continent during the 2010-2011 La Niña. Based on GRACE observations, they highlighted regional spots of much higher wetness than normal, 
particularly in northern Australia. This is illustrated in Fig 3 showing GRACE-based water storage anomalies in Australia over a period of 8 months from June 2010 to February 2011. This information can be associated to the anomaly in total water storage including surface water and groundwater with respect to long term average. While Fig 4 shows the excess and deficit information from the SMOSbased root zone soil moisture during February 2011 compared to the seasonal averages. The maps in Fig 3 and Fig 4 show similar patterns in several regions but also discrepancies that can be explained by the associated representative time period for each observed component by the two satellites that are complementary.

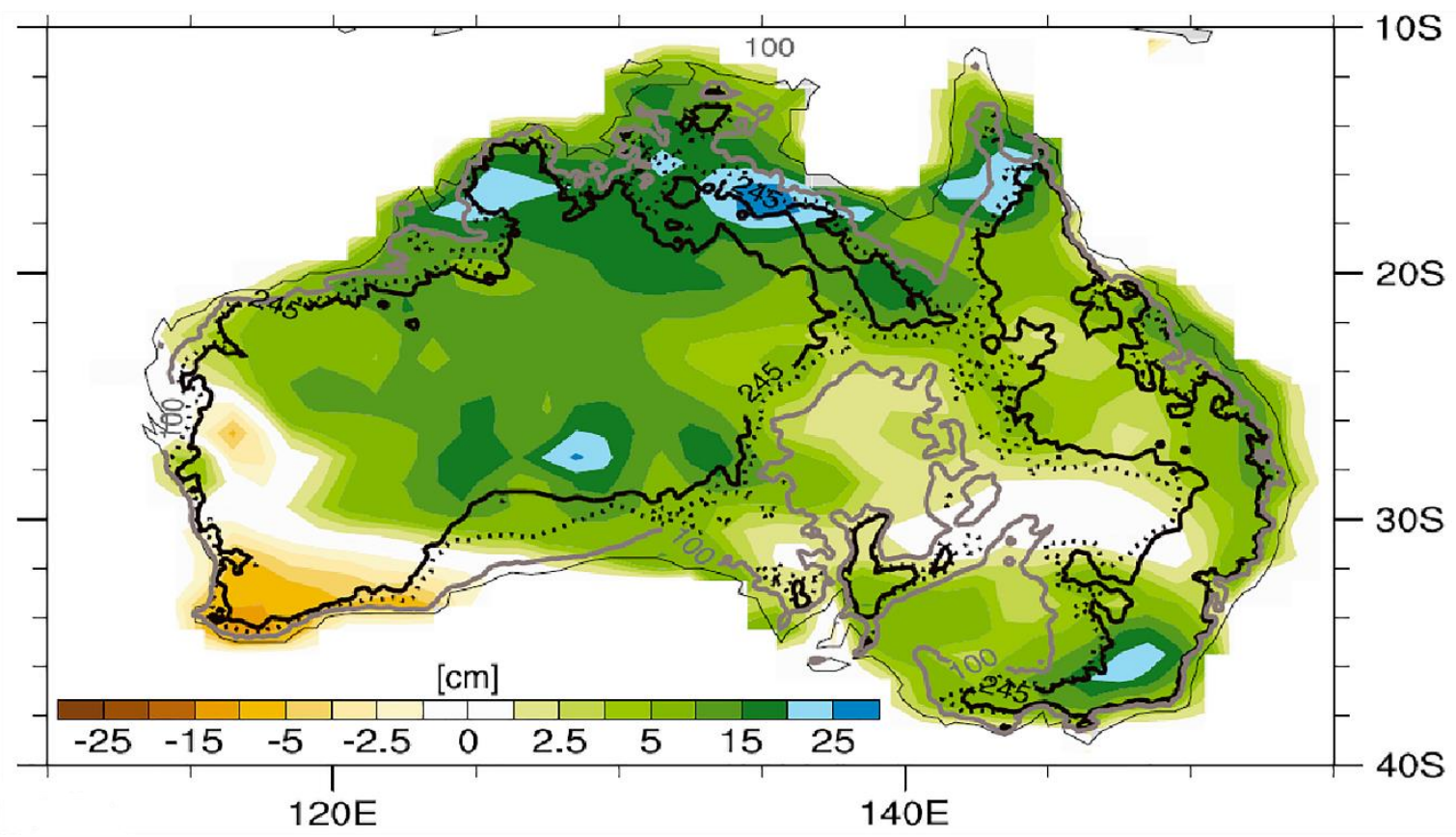

Fig 3 Water storage anomaly (expressed in cm of equivalent water height) for Australia based on GRACE for the period June 2010 to February 2011 (modified from Fasullo et al. 2013).

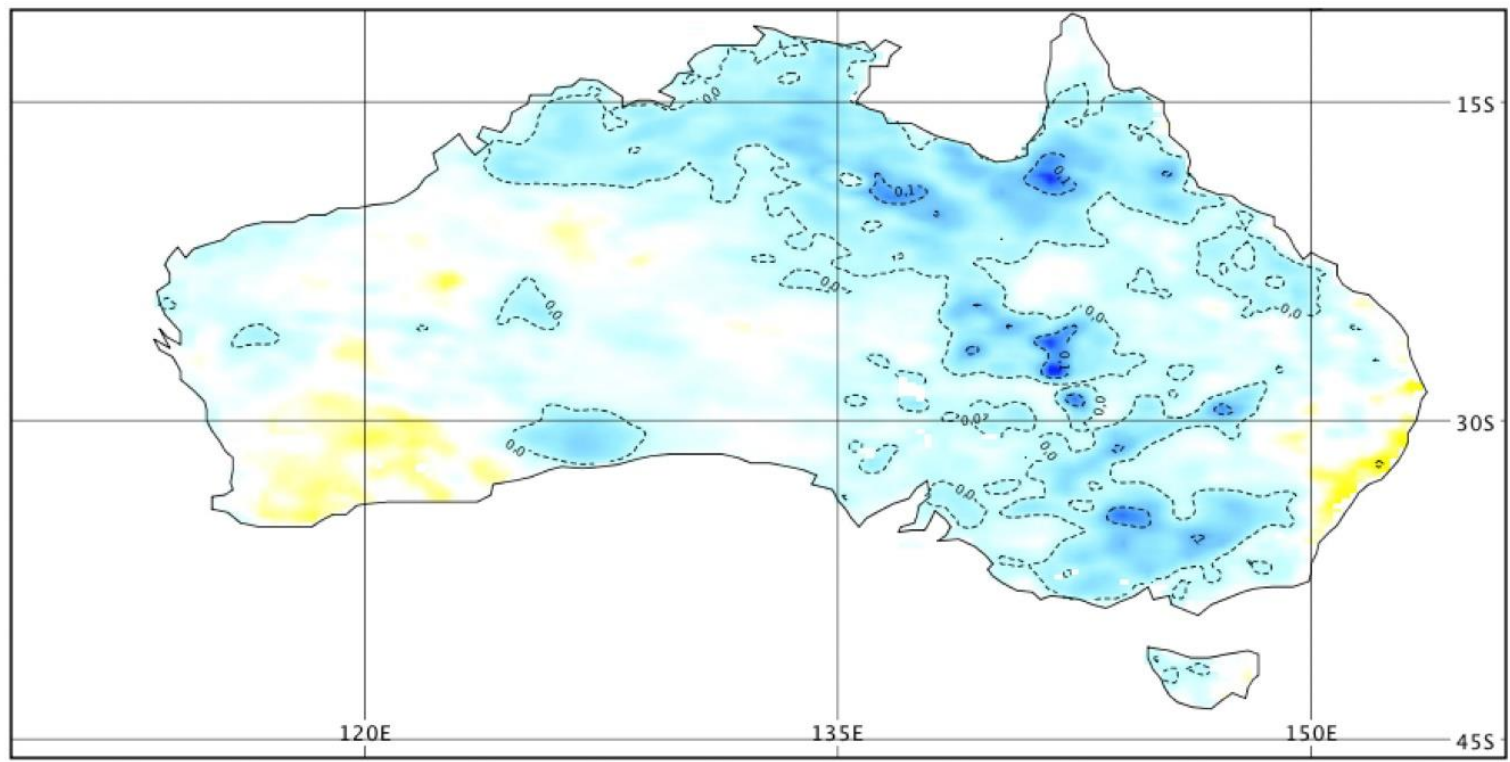

Deficit/excess in root zone soil moisture (m3. m-3)

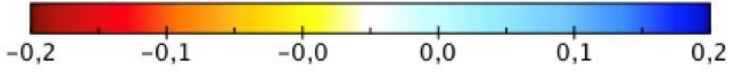

Fig 4 Root zone soil moisture deficit and excess over Australia in $m^{3} \mathrm{~m}^{-3}$ for February 2011 based on SMOS root zone soil moisture. 
Zhou et al. (2017) exploited TWS observations from the temporal gravity field model HUSTGrace2016, which was developed by a new low-frequency noise processing strategy, for identifying flood events in the Yangtze river basin and its sub-basins. 'Universal' floods were found in 2010, 2012 and 2016, while a 'regional' flood was observed in 2003. Similarly, Sun et al. (2017) showed for the Yangtze river basin that GRACE water storage anomalies and a GRACE-based flood potential index could effectively monitor large-scale flood events.

Following a probabilistic approach of the occurrence frequency and the expected return levels of hydrological extremes (i.e. the expected anomalous flux or storage values once in $\mathrm{N}$ years), Kusche et al. (2016) mapped these statistics on a global scale. They identified hot spots of anomalously high-water storage that can be related to flood events with good statistical significance despite a quite short time period of 144 months of GRACE data. Moreover, they predicted that with the continuation of the GRACE mission by GRACE-FO, it would be possible by around the year 2020 to detect changes in the frequency of total fluxes for at least $10-20 \%$ of the continental area.

While all flood analyses mentioned before used standard monthly GRACE products, Gouweleeuw et al. (2018) were the first to assess daily GRACE data for flood monitoring. They analysed two daily gravity field solutions based on GRACE observations and evaluated them against daily river runoff data for major flood events in the Ganges-Brahmaputra Delta (GBD) in 2004 and 2007. They found that variations over periods of a few days of the daily GRACE data reflect temporal variations in daily river runoff during major flood events. This confirmed in particular the potential of daily GRACE gravity field solutions based on a Kalman filter approach for gravity-based large-scale flood monitoring. They concluded that the release of daily GRACE gravity field solutions in near-real time may enable flood monitoring for large events. Gruber and Gouweleeuw (2019) further detailed how GRACE dynamic measurements and empirical external covariance information can be combined in the Kalman filter approach for the daily, short-latency mass changes products and reported on an evaluation of the product for describing flood dynamics in the Mekong delta.

Instead of using GRACE data after conversion to a data set of surface mass variations, Han et al. (2009) studied the terrestrial water storage in the Amazon basin and its surrounding areas by exploring directly the instantaneous measurements of distance changes between two satellites from the GRACE mission. These measurements are directly influenced by large water masses in the river network and adjacent floodplains and are thus potentially sensitive to flood dynamics. Han et al. (2009) anticipated that the assimilation of GRACE inter-satellite range-rate data will improve the surface water models by tuning the effective flow velocities within the large basins. Following a similar concept, Ghobadi-Far et al. (2018) developed a transfer function to determine the in situ line-of-sight gravity difference (LGD) directly from GRACE range-acceleration measurements. They demonstrated the use of LGD data based on forward computation of the gravity effects from hydrological models and comparison with the GRACE LGD data and concluded that the approach could serve as a tool suitable to study mass changes at high temporal resolution, including near real-time monitoring of floods.

\subsubsection{GRACE-based Flood Indicators and Flood Potential Assessment}

In the studies mentioned above, GRACE provided information on water storage anomalies in floodaffected regions for the event period itself. This is a valuable contribution for assessing the impact of the hydrological event on the water cycle in terms of magnitude and duration. Several studies, however, also explored the potential of GRACE information in a predictive way for forecasting flood events. The fundamental concept behind this is that the GRACE mass anomalies describe the wetness state of a river basin, which in turn is a key factor for flood generation. Wet pre-conditions in the sense of high, i.e. near-surface groundwater levels, close to saturated soils or filled surface water bodies indicate a reduced ability of the river basin to store additional water that comes with the next rainfall event. Thus, the probability that much of this rainfall becomes runoff and eventually generates a flood is increased. On this basis, Reager and Famiglietti (2009) estimated the flood potential of a region by inferring its storage capacity from the repeated maxima of the monthly time series of GRACE water storage anomalies. The flood potential is then defined as the actual water storage anomaly relative to the storage capacity. 
Molodtsova et al. (2016) evaluated this flood potential index for a large number of floods in the US and demonstrated its skill in particular for predicting large-area, long-duration floods in the summer season that are rainfall driven. Idowu and Zhou (2019) confirmed the value of the flood potential index for indicating flood events in the Niger basin. Eventually Jäggi et al. (2019) presented a wetness index based on daily GRACE water storage data. They showed for the example for the Danube basin that the index exceeded threshold values several weeks before the flood peak, making it a potentially useful candidate for early flood warning.

Reager et al. (2014) further developed the flood potential concept towards predicting flood discharge by an autoregressive model, driven with water storage anomalies. They showed that the GRACE-based information on elevated total water storage could improve the prediction with lead times of several months for the example of the Mississippi flood in 2011. With a similar approach for a Ganges subbasin, Chinnasamy (2017) confirmed that adding GRACE-based water storage anomalies improved flood discharge prediction with long lead times in comparison to a model that relies on precipitation only. Also, Chao and Wang (2017), for the Yangtze river basin, showed with a time-lagged autoregressive model that TWS changes from GRACE were effective for characterizing flood potential and for flood early warning with lead times of several months.

Beyond statistical forecast models as used in the studies mentioned before, integration of GRACE-based water storage anomalies into physically based hydrological and flood forecasting models may allow for additional early warning applications. As a first example, Reager et al. (2015) assimilated GRACE water storage anomalies into a hydrological model. For the 2011 Missouri flood, flood generation understanding, and modelling could be improved by resulting in wetter pre-event conditions and by providing more detailed information on the contributions of different storage compartments to the preevent flood potential.

\section{Progress in Drought Applications}

Droughts are the costliest hydrological events in terms of economic, environmental and human life losses and they impact a broad variety of regions in the world (e.g. Zhang and Jia 2013; Bayissa et al. 2017 and references therein). They are generally controlled by a deficit of groundwater, water available in the unsaturated zone, or in surface water bodies. They can be classified (e.g. Wilhite 2000; Zhang and Jia 2013; Du et al. 2019 and references therein) as meteorological droughts that are mainly associated to a deficit of precipitation and/or an increase of potential evapotranspiration. They can also be caused by sea surface temperature anomalies that lead to persistent continental drought while a warm temperature with low precipitation over a short period of time generates flash drought. Agricultural droughts are driven by a deficit of soil moisture associated or not with a deficiency of surface/subsurface water supply, i.e., hydrological droughts. The latter can also be described as socio-economic droughts where the available water is insufficient to cover the demand of some socio-economic goods and/or habits. This may induce a slower-progressing drought along with a deficiency of TWS and more particularly of groundwater availability. These different types of drought can occur alone but most of the time, a meteorological drought triggers the other ones. 


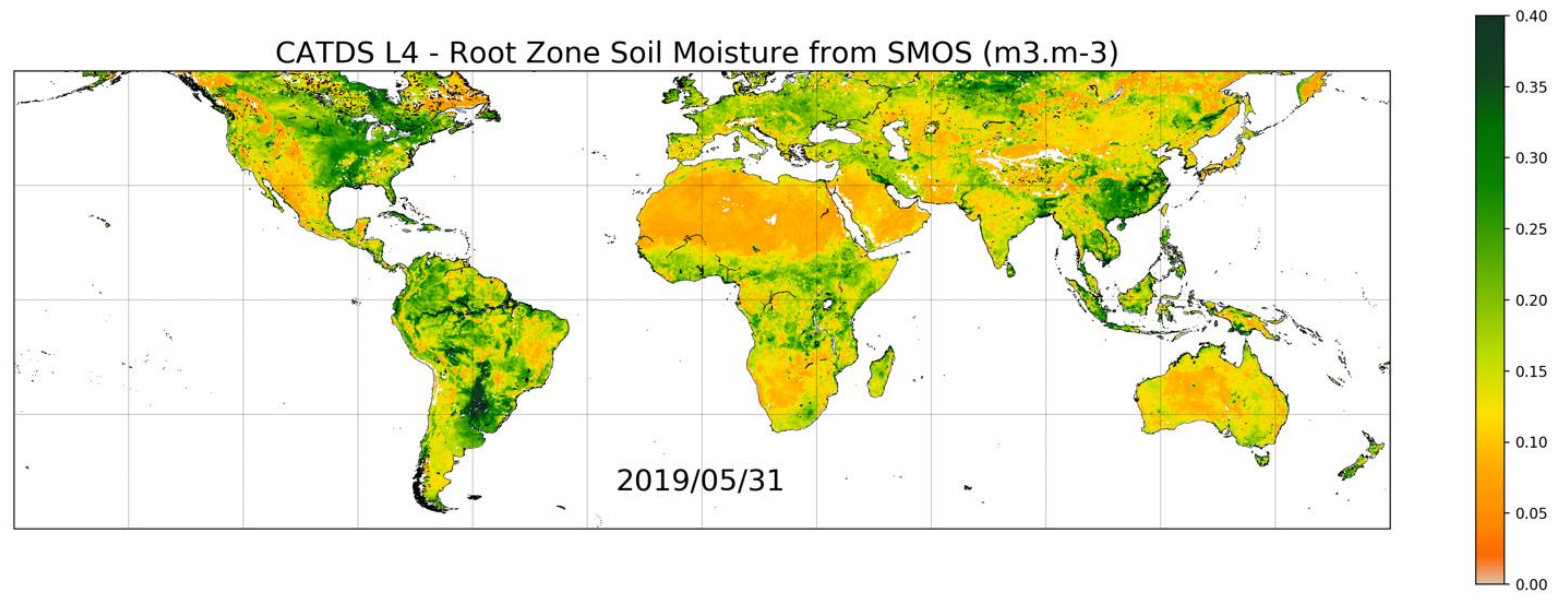

Fig 5 Global root-zone soil moisture in $\mathrm{m}^{3} \mathrm{~m}^{-3}$ obtained from SMOS surface soil moisture at $25 \mathrm{~km}$ resolution using a parsimonious model for 31 May 2019.

\subsection{Agricultural Droughts of 2019 from L-Band Radiometers}

One major information related to agricultural drought assessment is the water availability in the root zone. The definition of the water availability and root zone depth depends on the observed cropping type, phase of development and irrigation practices, but it is generally admitted that the root zone definition of crops at large scale is related to the first meter of soil and the water availability is defined as percentage of available water between the wilting point and the field capacity associated to the soil texture. The root zone soil moisture is not directly accessible currently by remote sensing technologies. Some studies addressed through local radiometers the capacity of future P-Band mission from active or passive remote sensing to measure root zone soil moisture (Garrison et al. 2018), but there is currently no operational satellite in this bandwidth. Still, root zone soil moisture can be indirectly quantified from remote sensing through vegetation stress condition (Swain et al. 2013), TWS, or the link between precipitation, surface and root zone soil moisture. The vegetation stress condition can be monitored using thermal remote sensing (Anderson et al. 2007) which provides an a-posteriori information about drought as the vegetation starts to show water stress after available water depletes. As mentioned in previous sections, TWS information can be acquired using gravimetric data at a coarse spatial resolution and root zone soil moisture may be singled out by removing the contributions from other water storage compartments if available, or by modelling via TWS data assimilation. The link between surface soil moisture and root zone soil moisture is more direct. Fig. 5 shows the root zone soil moisture obtained from the surface soil moisture SMOS data used in a parsimonious model. The model is based on two steps. First an exponential function is used to update the rootzone soil moisture based on the observed one. Second a soil model is used to compute the infiltration and vegetation extraction through computation of transpiration. In this case the MODIS NDVI data is used to compute the FAO56 crop index KC (Er-Raki et al. 2009).

CATDS L4 - Drought Index from SMOS Root Zone SM

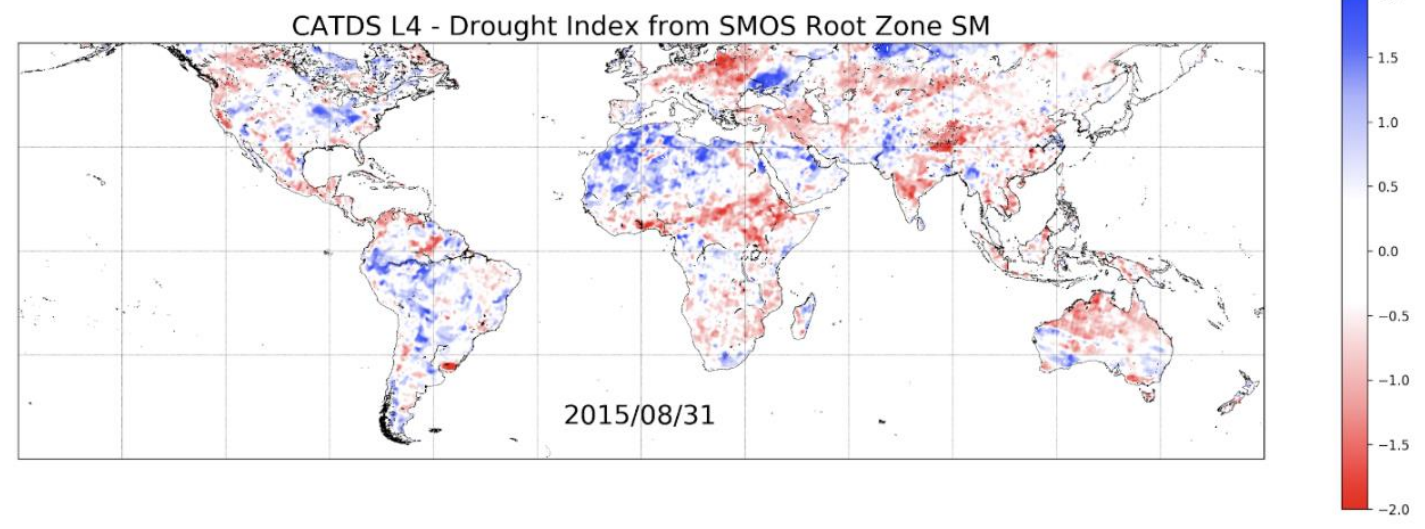




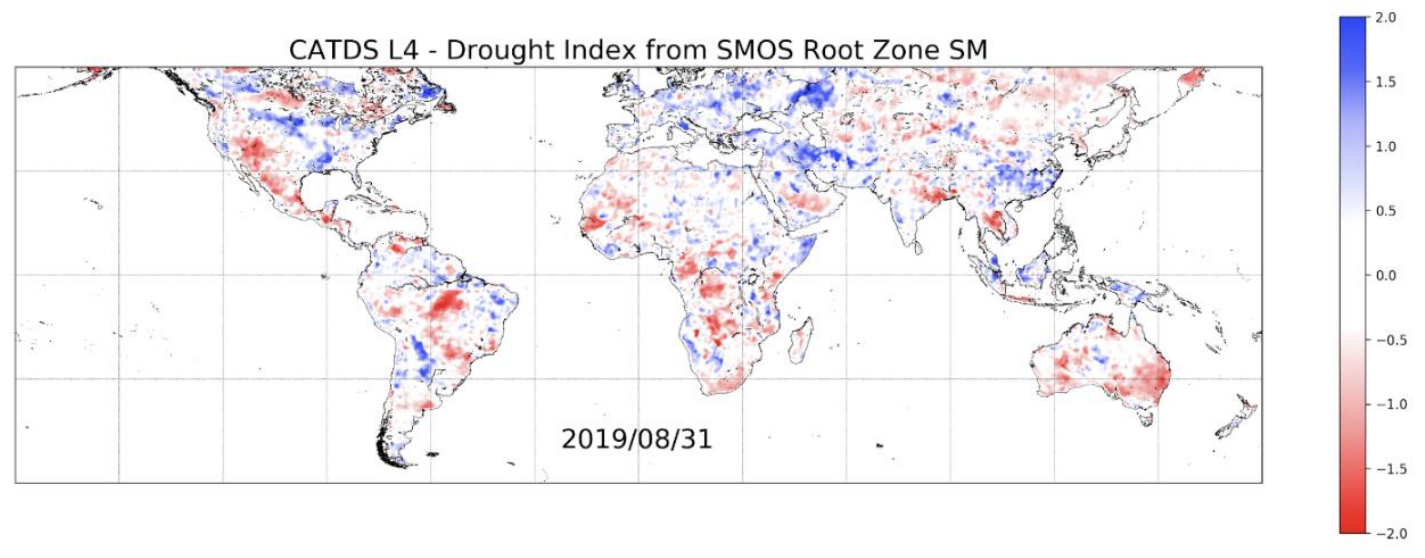

Fig 6 Global drought index obtained from the SMOS root zone soil moisture for August 2015 (upper panel) and August 2019 (lower panel).

Once a rootzone soil moisture is obtained, agricultural drought indicators can be determined. Al Bitar et al. (2013) and Kerr et al. (2016) defined the drought based on the standard anomaly index where an empirical cumulative density function is fitted to the timeseries statistics at each node and the drought is defined on probability thresholds. Fig 6 shows the drought index defined as root zone soil moisture anomalies for August 2015 and August 2019. The figure clearly shows the increase of the increase of droughts in 2019 to an already dry condition in 2015 leading to the massive forest fires in Australia. The figure also shows the dramatic conditions in large parts of Amazonia and in South Africa in 2019.

The main advantage of the use of passive L-Band remote sensing for agricultural drought monitoring is that, when combined with a parsimonious depth-scaling model, it provides the closest information to the state variable of interest, i.e. the root zone soil moisture.

\subsection{Droughts of Amazon Basin of 2010 observed by SMOS Water Fractions}

Anomalies of the extent of water surfaces may represent droughts that have an impact on wetlands and floodplains and can thus be classified as indicators of hydrological drought. Fig 7 shows two complementary information layers on meteorological and hydrological drought conditions over the Amazonian basin for the 2010 drought event. Fig 7a shows the anomalies obtained from rainfall data (adapted from Lewis et al. 2011) while Fig 7b shows the anomalies of water surface extent during the drought event. These water surface anomalies, expressed as anomalies of the surface water areal fraction (SWAF) in $25 \mathrm{~km}$ grid cells have been derived from SMOS by Parrens et al. (2017). They show two facets of this drought event that impacted the rainforest and the floodplains. The two components of this drought event had dramatic consequences on the ecosystem. While the meteorological drought had a direct impact on biomass and thus the carbon budget, the hydrological drought had an impact on the Amazon river floodplains and Bolivian wetlands ecosystem in the south of the basin. 


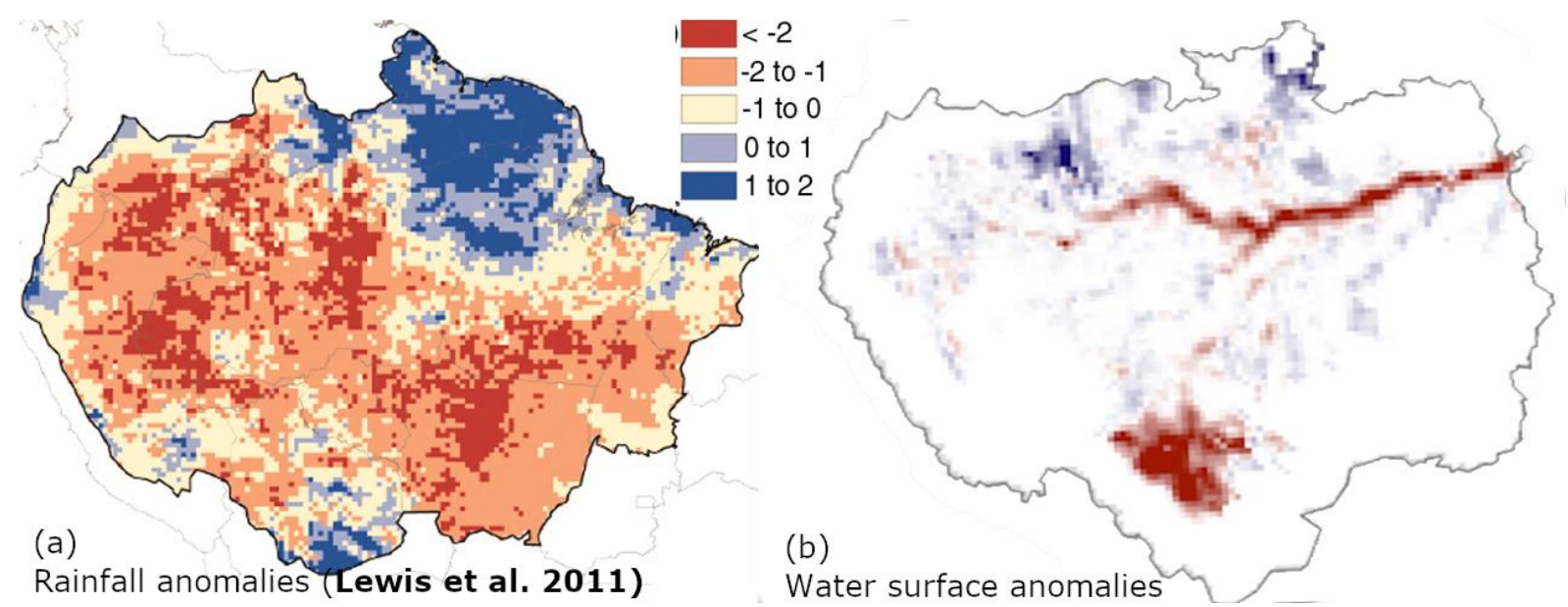

Fig 1 Standardized anomalies of a rainfall (adapted from Lewis et al. 2011) and $\boldsymbol{b}$ water surfaces based on the surface water areal fraction (SWAF) (Parrens et al. 2017) over the Amazon river basin during the 2010 drought event.

\subsection{Monitoring and Predicting Drought Events With GRACE-Based Gravimetry}

TWS estimations from GRACE give useful information about the water content variations through all the compartments at large spatial scale and over more than a decade. In order to better characterise droughts, information concerning water variations of all compartments are crucial and thus justifies the use of GRACE TWS estimations for droughts monitoring (e.g. Rodell 2012). Moreover, the drought event that impacted Texas in 2011 demonstrated that the depletion of water observed by GRACE is dominated by changes in soil moisture storage (Long et al. 2013). Since its launch, in different regions of the world, droughts have been observed directly with GRACE TWS data as for example in the Amazon river basin (Chen et al. 2009) and in Texas (Long et al. 2013). It has also demonstrated its ability to monitor droughts that affected several tropical basins during an El Niño event. For example, the 2015-2016 El Niño led to one of the most intense droughts ever recorded over southern Africa (e.g. Siderius et al. 2018). This event prevented groundwater recharge, hence produced groundwater decline over two consecutive years as reported from an analysis of GRACE data (Kolusu et al. 2019).

Some methods have been proposed to better characterise droughts by detecting anomalies in the TWS series (Thomas et al. 2014) and with the Normalized GRACE-derived groundwater storage deviation that permit quantification of the groundwater storage deficit (Thomas et al. 2017). Meanwhile, various drought indices obtained from GRACE have been used, e.g. the Drought Severity Index (DSI) and the Total Storage Deficit Index (Cao et al. 2015; Zhao et al. 2017; Nie et al. 2018). These partial examples demonstrate the interest and the ability of GRACE to allows globally consistent and effective drought monitoring. Two disadvantages of GRACE data for the monitoring of droughts are 1) the short period of time acquisition regarding the monitoring of drought events over several decades and 2) the spatial resolution. Concerning the short-time period of acquisitions, Long et al. (2014) and Zhang et al. (2016) developed a method based on artificial neural network approach to reconstruct longer TWS series from which it is possible to observe past drought events. In order to compensate the low spatial resolution of GRACE, some studies have demonstrated the benefits of GRACE data assimilation into land surface models, allowing spatial and temporal downscaling and providing information about groundwater and soil moisture by vertical decomposition (Houborg et al. 2012; Li et al. 2012). Despite their limitations, GRACE TWS estimations are the only information that permit the monitoring of droughts in regions where in situ data are sparse or inexistent. On the contrary, complementing in situ measurements and modelling, these estimations are extremely useful for groundwater resource management, especially during ENSO-driven events. Moreover, assimilation of GRACE and other data into regional/global hydrological models may be of great value to forecast floods and droughts events affecting river basins. 


\section{Future of Earth Observations for Large-Scale Flood and Drought Surveys}

\subsection{Future Altimetry Missions}

Jason-3 (launched in 2016), Sentinel-3A (launched in 2016) and Sentinel-3B (launched in 2018) are the nadir radar altimetry missions currently in operation at the time of writing. A new nadir altimetry mission (Sentinel-6A) will be launched in 2020 on the same nominal orbit as the Jason series. However, to alleviate nadir altimetry important observation gaps, the Surface Water and Ocean Topography (SWOT) mission will be launched in early 2022. SWOT will provide 2-D images of water surface topography, which should enhance hydrological hazards observation at least spatially. SWOT will observe all rivers wider than $100 \mathrm{~m}$ (with a goal to go down to $50 \mathrm{~m}$ ) and all water bodies with an area above $250 \mathrm{~m} \times 250 \mathrm{~m}$, i.e. $62,500 \mathrm{~m}^{2}$ (with a goal to go down to $100 \mathrm{~m} \times 100 \mathrm{~m}$ ) (Desai 2018). The main payload will measure water topography over two $50 \mathrm{~km}$ wide swaths. It will observe $96.5 \%$ of continents between $78^{\circ} \mathrm{S}$ and $78^{\circ} \mathrm{N}$ (Biancamaria et al. 2016), providing an almost global coverage of all water bodies on continental surfaces (see Fig 8 for SWOT coverage over the Ganges/Brahmaputra basin). If the repeat period of the orbit is 21 days, thanks to swaths overlaps, it will observe many regions multiple times during one repeat period (Fig 8). Compared to nadir or even SAR altimeters, SWOT will provide unprecedented spatial observations of water elevation, along with water area and river surface slope. From these measurements, global estimates of water storage change and river discharge will be derived (Durand et al. 2016; Desai 2018), which are essential for water management.

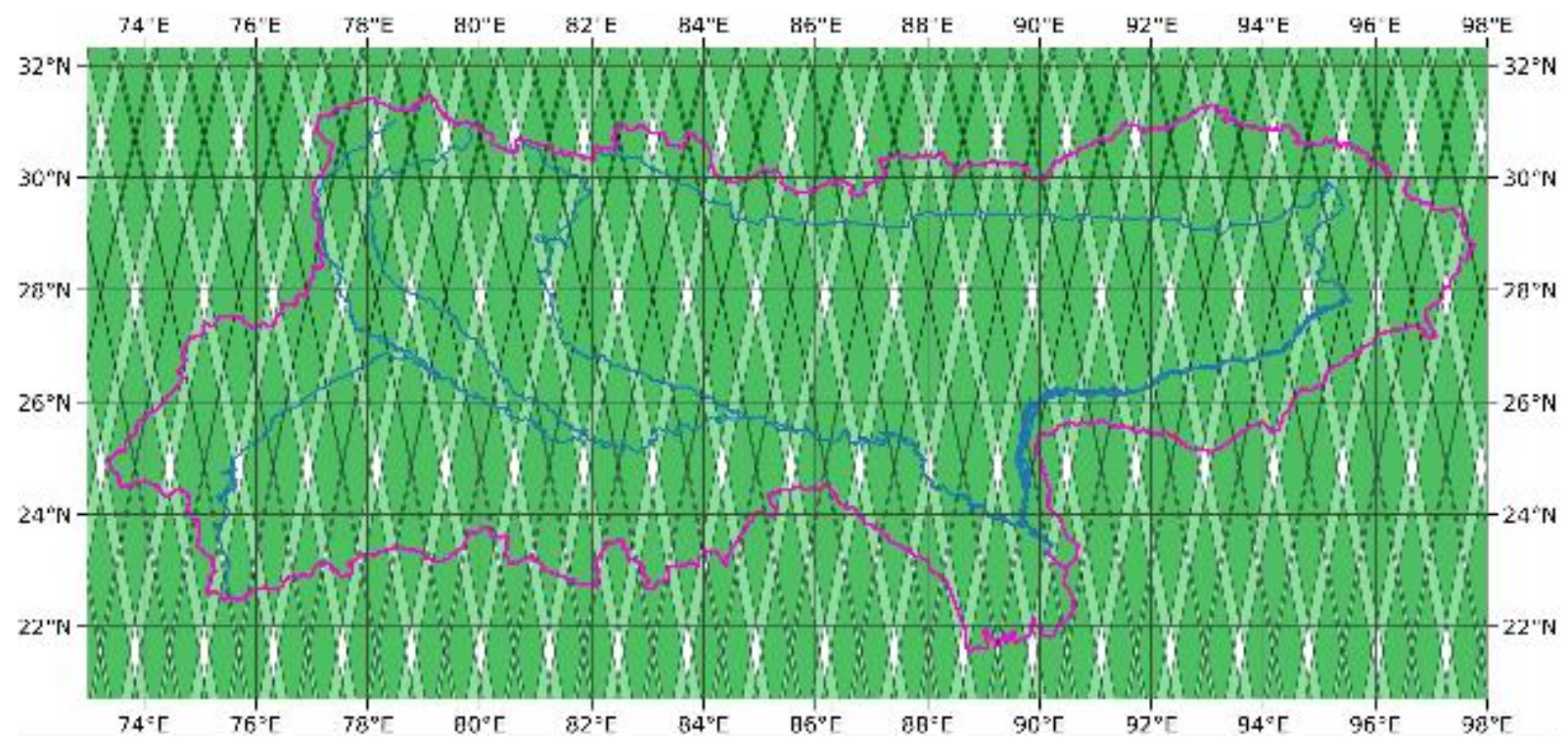

Fig 8 SWOT coverage (green polygons) over the Ganges/Brahmaputra basins (magenta boundaries). Light green corresponds to regions with one SWOT observation during a satellite repeat period (21 days), green regions correspond to two observations during a repeat period, whereas white regions will never be observed by SWOT. Blue lines represent the Ganges river and its major tributaries, and the Brahmaputra river

Despite its almost global coverage, SWOT will not be able to observe floods lasting only a few days or less, because of its still coarse time sampling. Frasson et al. (2019) investigated specifically the question of flood observability with SWOT. Comparing the 4,664 past flood events reported in the Dartmouth Flood Observatory database with SWOT orbit, they concluded that "SWOT would have seen $55 \%$ of these, with higher probabilities associated with more extreme events and with those that displaced more than 10,000 people". More specifically over the Cumberland River basin within continental US, Yoon et al. (2016) estimated that SWOT has "only a 5\% chance of direct observations of the 2-day flash flood event". Nonetheless, even if such new observations could help to forecast floods, SWOT uneven time sampling might be an issue. Therefore, SWOT will definitely improve large scale flood observation, but not smaller scale flood events. This issue could be somewhat alleviated using some DA techniques, 
currently under development, to derive enhanced space and time sampling discharge time series by taking advantages of the unprecedented SWOT spatial coverage over large to medium river basins (Brisset et al. 2018; Oubanas et al. 2018; Yang et al. 2019).

It is also expected that SWOT will be better suited than nadir altimeter to calibrate/correct model parameters thanks to its spatial coverage (Yoon et al. 2012; Pedinotti et al. 2014; Boergens et al. 2019), which then could provide better forecasts.

Benefits of SWOT DA into hydraulic or hydrological models have also been investigated to optimize reservoir control for flood mitigation in the Cumberland River basin (Yoon et al. 2016), to guarantee minimum flow within the upper Niger River basin (Munier et al. 2015) and to forecast some flood events within the Ohio River basin (Andreadis and Schumann 2014). Especially, this latter study estimated that assimilating SWOT data into a hydraulic model should help to forecast water height up to lead times of 11 days. However, it is still unclear how SWOT data will be effectively used into operational forecast systems, as SWOT wide swath products might not be delivered in real time (the time latency should be less than 45 days, according to SWOT Product Description Documents for hydrology surfaces) and its required nominal lifetime is only 3 years, with a goal to go up to 5 years (Desai 2018).

Space and time samplings of nadir altimetry missions limit the use of these sensors to observe and even more to forecast floods that last few days or less. In comparison, SWOT wide swath altimetry will provide global coverage, but its time sampling also restricts flood observation to major floods (Frasson et al. 2019). To improve samplings, a constellation of satellites seems to be a good option, as no single orbit will allow both frequent time and space samplings. The Centre National d'Etudes Spatiales (CNES) in France is currently proposing a constellation of two satellites with a wide swath altimeter, as potential candidate to the Copernicus - Next Generation Sentinel-3 Topography program (after 2030). It should observe similar water bodies as SWOT, but with a better time sampling ( 10 days) and a longer lifetime more suitable for operational use (Cheymol et al. 2019). To increase temporal sampling, CNES is also studying the feasibility of a constellation of nadir altimeters optimized for inland water bodies, called SMall Altimetry Satellites for Hydrology (SMASH) (Blumstein et al. 2019). It should provide daily measurements of water elevation with $10 \mathrm{~cm}$ accuracy, a data latency of less than 6 hours, and a long mission lifetime (> 10 years), particularly well-suited for operational applications.

\subsection{Future of L-Band Microwave EO}

L-Band EO data for flood and drought applications currently are provided by the SMOS and SMAP missions which are active since 2010 and 2015, respectively, with both missions beyond their nominal lifetime of 3 years. The continuity of L-Band observation is under study in the context of the ESA future Copernicus Imaging Microwave Radiometer (CIMR). If L-Band observation is confirmed aboard, this will ensure the continuity of the L-Band acquisitions but will not meet the needs expressed by the scientific community (Escorihuela and Kerr 2018) with respect to the spatial resolution. Actually, the L-Band radiometer on board CIMR is foreseen to have a coarser resolution than SMOS due to the mesh antenna size. Other initiatives for high resolution like SMOS-HR are under investigation at CNES (Rodríguez-Fernández et al. 2019). It is worth mentioning that the future NISAR (NASA/ISRO) mission which will include an S-Band and L-Band SAR will provide interesting opportunities for soil moisture and groundwater subsidence monitoring.

\subsection{Future of Gravimetry Missions}

Space-based TWS estimates by gravity data currently rely only on GRACE-FO mission launched in 2018 (Flechtner et al. 2014), thus extending the 15-year long record of GRACE, in spite of a close to 1year gap (GRACE ended in October 2017). But only by ensuring continuous and further improved TWS measurements from space, numerous questions regarding the changes and dynamic processes in land hydrology, cryosphere, ocean, atmosphere and solid Earth can be addressed (Pail et al. 2015). The NASA Earth Science Decadal Survey Report (National Academies of Sciences, Engineering, and 
Medecine 2018) thus highlighted monitoring spaced-based TWS as one of five top priorities in Earth Observation for the next decade (National Academies of Sciences, Engineering, and Medecine 2018). Based on this prioritization, NASA is currently running various studies how a Next Generation Gravity Mission (NGGM) should be realized, e.g. in terms of the number of satellites (or satellite pairs), orbit configuration, and instrumentation. Also, ESA launched a feasibility study on NGGM with the use of Laser interferometer for ranging measurements (Dionisio et al. 2018). A NGGM based on the innovative observational concept of a high-low tracking formation with micrometre ranging accuracy (Pail et al. 2019) is currently being studied by CNES. Eventually also, the reversing of GNSS-based kinematic trajectories of Low Earth Orbiter constellations might be able to monitor groundwater evolution (e.g. Bezděk et al. 2016 and references therein).

\section{Conclusions}

This article presents a review on the major scientific and technical developments made since over more than 20 years with low and moderate resolution satellite-based datasets in order to promote their use for flood and drought prediction and monitoring. Satellite gravimetry, L-Band passive microwave Earth Observation and nadir altimetry provide unique opportunities to monitor total terrestrial water storage and its individual compartments, soil moisture, surface water level and extent and river discharge, i.e. key hydrological variables to understand, predict and monitor flood and drought events. In fact, GRACE / GRACE-FO, SMOS and nadir altimeters missions have considerably improved our knowledge on the evolution at large spatial and long temporal scale of these variables. New methods developed along with the use of these sensors offer a better estimation of the dynamics and magnitudes of flood events, as well as a better spatially distributed discharge estimation in river basins with sparse in-situ observations. Furthermore, a better estimation of the long-term evolution of groundwater storage and of the total wetness state of river basins as represented by gravity based TWS have been an asset to study the storage amplitude, duration and frequency of large-scale floods and to highlight important groundwater withdrawals or severe droughts. The most important benefit of using moderate to low spatial resolution sensors is their ability to provide a synoptic view of these events from the river basin to the global scale. Very often, this synoptic view cannot be achieved with often sparse in situ measurements or with remote sensing techniques of high resolution but low spatial coverage. Finally, the most promising perspective to increase the understanding, forecasting and mitigation of hydrological events will be to assimilate the moderate to low resolution satellite data into LSMs, combine them with higher spatial resolution data, either space- or UAV- based (Antoine et al. 2020) and to use new methodologies, involving Artificial Intelligence, for instance.

\section{Acknowledgements}

This paper arose from the international workshop on "Natural and man-made hazards monitoring by the Earth Observation missions: current status and scientific gaps" held at the International Space Science Institute (ISSI), Bern, Switzerland, on April 15-18, 2019. The authors wish to thank the two anonymous reviewers for their constructive suggestions which significantly improved this article; Dr. Anny Cazenave, for her invitation to prepare this paper and Anne-Marie Cousin for her help in producing Fig. 1. The final publication is available at https://link.springer.com/article/10.1007\%2Fs10712-020-09618-0 


\section{References}

Abelen S, Seitz F, Abarca-del-Rio R, Güntner A (2015) Droughts and Floods in the La Plata Basin in Soil Moisture Data and GRACE. Remote Sensing 7:7324-7349. https://doi.org/10.3390/rs70607324

Aires F, Miolane L, Prigent C, et al (2017) A Global Dynamic Long-Term Inundation Extent Dataset at High Spatial Resolution Derived through Downscaling of Satellite Observations. J Hydrometeor 18:1305-1325. https://doi.org/10.1175/JHM-D-16-0155.1

Al Bitar A, Kerr Y, Merlin O, et al (2013) Root zone soil moisture and drought index from SMOS. In: Satellite Soil Moisture Validation and Application Workshop. 2013-07-012013-07-03, Frascati, ITA

Al Bitar A, Mialon A, Kerr Y, et al (2017) The Global SMOS Level 3 daily soil moisture and brightness temperature maps. Earth System Science Data 9:293-315. https://doi.org/10.5194/essd-9-2932017

Al Bitar A, Parrens M, Frappart F, et al (2016) How are the wetlands over tropical basins impacted by the extreme hydrological events? AGU Fall Meeting Abstracts 51:

Albergel C, Rüdiger C, Pellarin T, et al (2008) From near-surface to root-zone soil moisture using an exponential filter: an assessment of the method based on in-situ observations and model simulations. Hydrology and Earth System Sciences 12:1323-1337. https://doi.org/10.5194/hess-12-1323-2008

Anderson MC, Norman JM, Mecikalski JR, et al (2007) A climatological study of evapotranspiration and moisture stress across the continental United States based on thermal remote sensing: 2 . Surface moisture climatology. Journal of Geophysical Research: Atmospheres 112:. https://doi.org/10.1029/2006JD007507

Andreadis KM, Schumann GJ-P (2014) Estimating the impact of satellite observations on the predictability of large-scale hydraulic models. Advances in Water Resources 73:44-54. https://doi.org/10.1016/j.advwatres.2014.06.006

Antoine R, Fauchard C, Gaillet L, et al (2020) Geoscientists in the sky: Unmanned Aerial Vehicles for geohazards response. Surveys in Geophysics 41:. https://doi.org/10.1007/s10712-020-09611-7

Babaeian E, Sadeghi M, Jones SB, et al (2019) Ground, Proximal, and Satellite Remote Sensing of Soil Moisture. Reviews of Geophysics 57:530-616. https://doi.org/10.1029/2018RG000618

Bates PD, Neal JC, Alsdorf D, Schumann GJ-P (2014) Observing Global Surface Water Flood Dynamics. Surveys in Geophysics 35:839-852. https://doi.org/10.1007/s10712-013-9269-4

Bayissa Y, Tadesse T, Demisse G, Shiferaw A (2017) Evaluation of Satellite-Based Rainfall Estimates and Application to Monitor Meteorological Drought for the Upper Blue Nile Basin, Ethiopia. Remote Sensing 9:669. https://doi.org/10.3390/rs9070669

Bezděk A, Sebera J, Teixeira da Encarnação J, Klokočník J (2016) Time-variable gravity fields derived from GPS tracking of Swarm. Geophysical Journal International 205:1665-1669. https://doi.org/10.1093/gji/ggw094

Biancamaria S, Hossain F, Lettenmaier DP (2011) Forecasting transboundary river water elevations from space. Geophysical Research Letters 38:n/a-n/a. https://doi.org/10.1029/2011GL047290 
Biancamaria S, Lettenmaier DP, Pavelsky TM (2016) The SWOT Mission and Its Capabilities for Land Hydrology. Surveys in Geophysics 37:307-337. https://doi.org/10.1007/s10712-015-9346-y

Blumstein D, Guérin A, Lamy A, et al (2019) SMASH: A Constellation of Small Altimetry Satellites Dedicated to Hydrology. 6th Workshop on Advanced RF Sensors and Remote Sensing Instruments (ARSI'19) and 4th Ka-band Earth Observation Radar Missions Workshop (KEO'19). ESA-ESTEC, Noordwijk, The Netherlands

Boening C, Willis JK, Landerer FW, et al (2012) The 2011 La Niña: So strong, the oceans fell: LA NIÑA 2011-SO STRONG, THE OCEANS FELL. Geophysical Research Letters 39:n/a-n/a. https://doi.org/10.1029/2012GL053055

Boergens E, Dettmering D, Seitz F (2019) Observing water level extremes in the Mekong River Basin: The benefit of long-repeat orbit missions in a multi-mission satellite altimetry approach. Journal of Hydrology 570:463-472. https://doi.org/10.1016/j.jhydrol.2018.12.041

Bojinski S, Verstraete M, Peterson TC, et al (2014) The Concept of Essential Climate Variables in Support of Climate Research, Applications, and Policy. Bull Amer Meteor Soc 95:1431-1443. https://doi.org/10.1175/BAMS-D-13-00047.1

Bonn F, Dixon R (2005) Monitoring Flood Extent and Forecasting Excess Runoff Risk with RADARSAT-1 Data. Nat Hazards 35:377-393. https://doi.org/10.1007/s11069-004-1798-1

Bonsor H, Shamsudduha M, Marchant B, et al (2018) Seasonal and Decadal Groundwater Changes in African Sedimentary Aquifers Estimated Using GRACE Products and LSMs. Remote Sensing 10:904. https://doi.org/10.3390/rs10060904

Brisset P, Monnier J, Garambois P-A, Roux H (2018) On the assimilation of altimetric data in 1D SaintVenant river flow models. Advances in Water Resources 119:41-59. https://doi.org/10.1016/j.advwatres.2018.06.004

Cao Y, Nan Z, Cheng G (2015) GRACE Gravity Satellite Observations of Terrestrial Water Storage Changes for Drought Characterization in the Arid Land of Northwestern China. Remote Sensing 7:1021-1047. https://doi.org/10.3390/rs70101021

Chao N, Wang Z (2017) Characterized Flood Potential in the Yangtze River Basin from GRACE Gravity Observation, Hydrological Model, and In-Situ Hydrological Station. Journal of Hydrologic Engineering 22:05017016. https://doi.org/10.1061/(ASCE)HE.1943-5584.0001547

Chen JL, Wilson CR, Tapley BD, et al (2016) Long-term groundwater storage change in Victoria, Australia from satellite gravity and in situ observations. Global and Planetary Change 139:5665. https://doi.org/10.1016/j.gloplacha.2016.01.002

Chen JL, Wilson CR, Tapley BD (2010) The 2009 exceptional Amazon flood and interannual terrestrial water storage change observed by GRACE: THE 2009 AMAZON FLOOD OBSERVED BY GRACE. Water Resources Research 46:. https://doi.org/10.1029/2010WR009383

Chen JL, Wilson CR, Tapley BD, et al (2009) 2005 drought event in the Amazon River basin as measured by GRACE and estimated by climate models. Journal of Geophysical Research: Solid Earth 114:. https://doi.org/10.1029/2008JB006056

Cheymol C, Coutin-Faye S, Le Traon P-Y, et al (2019) WiSA : a Wide Swath Altimetry Mission for Operational Oceanography and Hydrology A good candidate for Copernicus-NG Sentinel 3Topo Program 
Chinnasamy P (2017) Inference of basin flood potential using nonlinear hysteresis effect of basin water storage: case study of the Koshi basin. Hydrology Research 48:1554-1565. https://doi.org/10.2166/nh.2016.268

Coe MT, Birkett CM (2004) Calculation of river discharge and prediction of lake height from satellite radar altimetry: Example for the Lake Chad basin: CALCULATION OF RIVER DISCHARGE. Water Resources Research 40:. https://doi.org/10.1029/2003WR002543

Costa MPF, Silva TS, Evans TL (2013) Wetland classification. Remote Sensing of Natural Resources CRC Press, Boca Raton-FL 461-478

Desai S (2018) Surface Water and Ocean Topography Mission (SWOT) Project, Science Requirements Document. NASA/JPL technical document D-61923 Revision B:29

Dionisio S, Anselmi A, Bonino L, et al (2018) The "Next Generation Gravity Mission": challenges and consolidation of the system concepts and technological innovations. 15th International Conference on Space Operations. https://doi.org/10.2514/6.2018-2495

Döll P, Kaspar F, Lehner B (2003) A global hydrological model for deriving water availability indicators: model tuning and validation. Journal of Hydrology 270:105-134. https://doi.org/10.1016/S0022-1694(02)00283-4

Domeneghetti A, Schumann GJ-P, Tarpanelli A (2019) Preface: Remote Sensing for Flood Mapping and Monitoring of Flood Dynamics. Remote Sensing 11:943. https://doi.org/10.3390/rs11080943

Drinkwater M, Haagmans R, Muzi D, et al (2006) The GOCE gravity mission: ESA'sfirst core explorer. In: Proceedings 3rd GOCE User Workshop. Frascati, Italy, pp 1-7

Du J, Kimball JS, Velicogna I, et al (2019) Multicomponent Satellite Assessment of Drought Severity in the Contiguous United States From 2002 to 2017 Using AMSR-E and AMSR2. Water Resources Research 55:5394-5412. https://doi.org/10.1029/2018WR024633

Durand M, Gleason CJ, Garambois PA, et al (2016) An intercomparison of remote sensing river discharge estimation algorithms from measurements of river height, width, and slope: SWOT DISCHARGE ALGORITHM INTERCOMPARISON. Water Resources Research 52:45274549. https://doi.org/10.1002/2015WR018434

Emery CM, Paris A, Biancamaria S, et al (2018) Large-scale hydrological model river storage and discharge correction using a satellite altimetry-based discharge product. Hydrology and Earth System Sciences 22:2135-2162. https://doi.org/10.5194/hess-22-2135-2018

Entekhabi D, Njoku EG, O’Neill PE, et al (2010) The Soil Moisture Active Passive (SMAP) Mission. Proceedings of the IEEE 98:704-716. https://doi.org/10.1109/JPROC.2010.2043918

Er-Raki S, Chehbouni A, Guemouria N, et al (2009) Citrus orchard evapotranspiration: Comparison between eddy covariance measurements and the FAO-56 approach estimates. Plant Biosystems - An International Journal Dealing with all Aspects of Plant Biology 143:201-208. https://doi.org/10.1080/11263500802709897

Escorihuela MJ, Kerr Y (2018) Low frequency passive microwave user requirement consolidation study: D-02 white paper on L-band radiometry for earth observation: status and achievements

Famiglietti JS (2014) The global groundwater crisis. Nature Climate Change 4:945-948. https://doi.org/10.1038/nclimate2425 
Famiglietti JS, Lo M, Ho SL, et al (2011) Satellites measure recent rates of groundwater depletion in California's Central Valley. Geophysical Research Letters 38:L03403. https://doi.org/10.1029/2010GL046442

Fasullo JT, Boening C, Landerer FW, Nerem RS (2013) Australia's unique influence on global sea level in 2010-2011. Geophysical Research Letters 40:4368-4373. https://doi.org/10.1002/grl.50834

Finsen F, Milzow C, Smith R, et al (2014) Using radar altimetry to update a large-scale hydrological model of the Brahmaputra river basin. Hydrology Research 45:148-164. https://doi.org/10.2166/nh.2013.191

Flechtner F, Morton P, Watkins M, Webb F (2014) Status of the GRACE Follow-On Mission. Gravity, Geoid and Height Systems 117-121. https://doi.org/10.1007/978-3-319-10837-7_15

Fok H, He Q, Chun K, et al (2018) Application of ENSO and Drought Indices for Water Level Reconstruction and Prediction: A Case Study in the Lower Mekong River Estuary. Water 10:58. https://doi.org/10.3390/w10010058

Foster S, Loucks DP (2006) Non-renewable groundwater resources: a guidebook on socially-sustainable management for water-policy makers, United Nations Educational, Scientific and Cultural Organization. UNESCO, Paris, France

Frappart F, Ramillien G (2018) Monitoring Groundwater Storage Changes Using the Gravity Recovery and Climate Experiment (GRACE) Satellite Mission: A Review. Remote Sensing 10:829. https://doi.org/10.3390/rs10060829

Frappart F, Seyler F, Martinez J-M, et al (2005) Floodplain water storage in the Negro River basin estimated from microwave remote sensing of inundation area and water levels. Remote Sensing of Environment 99:387-399. https://doi.org/10.1016/j.rse.2005.08.016

Frasson RP de M, Schumann GJ -P., Kettner AJ, et al (2019) Will the Surface Water and Ocean Topography (SWOT) Satellite Mission Observe Floods? Geophysical Research Letters 46:10435-10445. https://doi.org/10.1029/2019GL084686

Garrison JL, Kurum M, Nold B, et al (2018) Remote Sensing of Root-Zone Soil Moisture Using I- and P-Band Signals of Opportunity: Instrument Validation Studies. IGARSS 2018 - 2018 IEEE International Geoscience and Remote Sensing Symposium 8305-8308. https://doi.org/10.1109/IGARSS.2018.8518772

Ghobadi-Far K, Han S-C, Weller S, et al (2018) A Transfer Function Between Line-of-Sight Gravity Difference and GRACE Intersatellite Ranging Data and an Application to Hydrological Surface Mass Variation. Journal of Geophysical Research: Solid Earth 123:9186-9201. https://doi.org/10.1029/2018JB016088

Gomez C, Dharumarajan S, Féret J-B, et al (2019) Use of Sentinel-2 Time-Series Images for Classification and Uncertainty Analysis of Inherent Biophysical Property: Case of Soil Texture Mapping. Remote Sensing 11:565. https://doi.org/10.3390/rs11050565

Gouweleeuw BT, Kvas A, Gruber C, et al (2018) Daily GRACE gravity field solutions track major flood events in the Ganges-Brahmaputra Delta. Hydrology and Earth System Sciences 22:28672880. https://doi.org/10.5194/hess-22-2867-2018

Grillakis MG, Koutroulis AG, Komma J, et al (2016) Initial soil moisture effects on flash flood generation - A comparison between basins of contrasting hydro-climatic conditions. Journal of Hydrology 541:206-217. https://doi.org/10.1016/j.jhydrol.2016.03.007 
Gruber C, Gouweleeuw B (2019) Short-latency monitoring of continental, ocean- and atmospheric mass variations using GRACE intersatellite accelerations. Geophysical Journal International 217:714-728. https://doi.org/10.1093/gji/ggz042

Han S-C, Kim H, Yeo I-Y, et al (2009) Dynamics of surface water storage in the Amazon inferred from measurements of inter-satellite distance change. Geophysical Research Letters 36:. https://doi.org/10.1029/2009GL037910

Hébert H, Gailler A, Gupta H, et al (2020) Contribution of space missions to a better tsunami science: observations, models and warning. Surveys in Geophysics 41:in press

Hillel D (1998) Environmental soil physics: Fundamentals, applications, and environmental considerations. Elsevier

Hirpa FA, Hopson TM, De Groeve T, et al (2013) Upstream satellite remote sensing for river discharge forecasting: Application to major rivers in South Asia. Remote Sensing of Environment 131:140-151. https://doi.org/10.1016/j.rse.2012.11.013

Hoekstra AY, Chapagain AK, Mekonnen MM, Aldaya MM (2011) The water footprint assessment manual: Setting the global standard. Routledge

Hossain F, Siddique-E-Akbor AH, Mazumder LC, et al (2014) Proof of Concept of an Altimeter-Based River Forecasting System for Transboundary Flow Inside Bangladesh. IEEE Journal of Selected Topics in Applied Earth Observations and Remote Sensing 7:587-601. https://doi.org/10.1109/JSTARS.2013.2283402

Houborg R, Rodell M, Li B, et al (2012) Drought indicators based on model-assimilated Gravity Recovery and Climate Experiment (GRACE) terrestrial water storage observations. Water Resources Research 48:. https://doi.org/10.1029/2011WR011291

Huntingford C, Marsh T, Scaife AA, et al (2014) Potential influences on the United Kingdom's floods of winter 2013/14. Nature Clim Change 4:769-777. https://doi.org/10.1038/nclimate2314

Idowu, Zhou (2019) Performance Evaluation of a Potential Component of an Early Flood Warning System-A Case Study of the 2012 Flood, Lower Niger River Basin, Nigeria. Remote Sensing 11:1970. https://doi.org/10.3390/rs11171970

Jäggi A, Weigelt M, Flechtner F, et al (2019) European Gravity Service for Improved Emergency Management (EGSIEM) - from concept to implementation. Geophysical Journal International 218:1572-1590. https://doi.org/10.1093/gji/ggz238

Jean Y, Meyer U, Jäggi A (2018) Combination of GRACE monthly gravity field solutions from different processing strategies. Journal of Geodesy 92:1313-1328. https://doi.org/10.1007/s00190-018$1123-5$

Jiang L, Madsen H, Bauer-Gottwein P (2019) Simultaneous calibration of multiple hydrodynamic model parameters using satellite altimetry observations of water surface elevation in the Songhua River. Remote Sensing of Environment 225:229-247. https://doi.org/10.1016/j.rse.2019.03.014

Kerr YH, Waldteufel P, Richaume P, et al (2012) The SMOS Soil Moisture Retrieval Algorithm. IEEE Transactions on Geoscience and Remote Sensing 50:1384-1403. https://doi.org/10.1109/TGRS.2012.2184548

Kerr YH, Wigneron J-P, Al Bitar A, et al (2016) Soil moisture from space: Techniques and limitations. Satellite Soil Moisture Retrieval 3-27. https://doi.org/10.1016/B978-0-12-803388-3.00001-2 
Kolusu SR, Shamsudduha M, Todd MC, et al (2019) The El Niño event of 2015-2016: climate anomalies and their impact on groundwater resources in East and Southern Africa. Hydrology and Earth System Sciences 23:1751-1762. https://doi.org/10.5194/hess-23-1751-2019

Kummu M, De Moel H, Ward PJ, Varis O (2011) How close do we live to water? A global analysis of population distance to freshwater bodies. PloS one 6:e20578. https://doi.org/10.1371/journal.pone.0020578

Kusche J, Eicker A, Forootan E, et al (2016) Mapping probabilities of extreme continental water storage changes from space gravimetry: MAPPING TWS EXTREMES FROM SPACE. Geophysical Research Letters 43:8026-8034. https://doi.org/10.1002/2016GL069538

Landerer FW, Flechtner FM, Save H, et al (2020) Extending the Global Mass Change Data Record: GRACE Follow-On Instrument and Science Data Performance. Geophysical Research Letters 47:e2020GL088306. https://doi.org/10.1029/2020GL088306

Lewis SL, Brando PM, Phillips OL, et al (2011) The 2010 Amazon Drought. Science 331:554-554. https://doi.org/10.1126/science.1200807

Li B, Rodell M, Zaitchik BF, et al (2012) Assimilation of GRACE terrestrial water storage into a land surface model: Evaluation and potential value for drought monitoring in western and central Europe. Journal of Hydrology 446-447:103-115. https://doi.org/10.1016/j.jhydrol.2012.04.035

Lissak C, De Michele M, Bartsch A, et al (2020) Remote sensing for mass movement assessment. Surveys in Geophysics 41:in press

Long D, Scanlon BR, Longuevergne L, et al (2013) GRACE satellite monitoring of large depletion in water storage in response to the 2011 drought in Texas: GRACE-BASED DROUGHT MONITORING. Geophysical Research Letters 40:3395-3401. https://doi.org/10.1002/grl.50655

Long D, Shen Y, Sun A, et al (2014) Drought and flood monitoring for a large karst plateau in Southwest China using extended GRACE data. Remote Sensing of Environment 155:145-160. https://doi.org/10.1016/j.rse.2014.08.006

Margat J, Van der Gun J (2013) Groundwater around the world: a geographic synopsis, CRC Press. Taylor \& Francis Group

Matgen P, Hostache R, Schumann G, et al (2011) Towards an automated SAR-based flood monitoring system: Lessons learned from two case studies. Physics and Chemistry of the Earth, Parts A/B/C 36:241-252. https://doi.org/10.1016/j.pce.2010.12.009

Melet A, Teatini P, Le Cozannet G, et al (2020) Earth Observations for Monitoring Marine Coastal Hazards and Their Drivers. Surveys in Geophysics. https://doi.org/10.1007/s10712-020-095945

Merlin O, Al Bitar A, Walker JP, Kerr Y (2010) An improved algorithm for disaggregating microwavederived soil moisture based on red, near-infrared and thermal-infrared data. Remote Sensing of Environment 114:2305-2316. https://doi.org/10.1016/j.rse.2010.05.007

Michailovsky CI, Milzow C, Bauer-Gottwein P (2013) Assimilation of radar altimetry to a routing model of the Brahmaputra River: Radar Altimetry to a Routing Model. Water Resources Research 49:4807-4816. https://doi.org/10.1002/wrcr.20345 
Molodtsova T, Molodtsov S, Kirilenko A, et al (2016) Evaluating flood potential with GRACE in the United States. Natural Hazards and Earth System Sciences 16:1011-1018. https://doi.org/10.5194/nhess-16-1011-2016

Mueller N, Lewis A, Roberts D, et al (2016) Water observations from space: Mapping surface water from 25years of Landsat imagery across Australia. Remote Sensing of Environment 174:341352. https://doi.org/10.1016/j.rse.2015.11.003

Munier S, Polebistki A, Brown C, et al (2015) SWOT data assimilation for operational reservoir management on the upper Niger River Basin. Water Resources Research 51:554-575. https://doi.org/10.1002/2014WR016157

National Academies of Sciences, Engineering, and Medecine (2018) Thriving on Our Changing Planet: A Decadal Strategy for Earth Observation from Space. https://doi.org/10.17226/24938

Nie N, Zhang W, Chen H, Guo H (2018) A Global Hydrological Drought Index Dataset Based on Gravity Recovery and Climate Experiment (GRACE) Data. Water Resour Manage 32:12751290. https://doi.org/10.1007/s11269-017-1869-1

Niu J, Chen J, Sivakumar B (2014) Teleconnection analysis of runoff and soil moisture over the Pearl River basin in southern China. Hydrology and Earth System Sciences 18:1475-1492. https://doi.org/10.5194/hess-18-1475-2014

Njoku EG, Jackson TJ, Lakshmi V, et al (2003) Soil moisture retrieval from AMSR-E. IEEE Transactions on Geoscience and Remote Sensing 41:215-229. https://doi.org/10.1109/TGRS.2002.808243

Oubanas H, Gejadze I, Malaterre P -O., et al (2018) Discharge Estimation in Ungauged Basins Through Variational Data Assimilation: The Potential of the SWOT Mission. Water Resources Research 54:2405-2423. https://doi.org/10.1002/2017WR021735

Ovando A, Martinez JM, Tomasella J, et al (2018) Multi-temporal flood mapping and satellite altimetry used to evaluate the flood dynamics of the Bolivian Amazon wetlands. International Journal of Applied Earth Observation and Geoinformation 69:27-40. https://doi.org/10.1016/j.jag.2018.02.013

Pail R, Bamber J, Biancale R, et al (2019) Mass variation observing system by high low inter-satellite links (MOBILE) - a new concept for sustained observation of mass transport from space. Journal of Geodetic Science 9:48-58. https://doi.org/10.1515/jogs-2019-0006

Pail R, Braitenberg C, Dobslaw H, et al (2015) Science and User Needs for Observing Global Mass Transport to Understand Global Change and to Benefit Society. Surveys in Geophysics 36:743772. https://doi.org/10.1007/s10712-015-9348-9

Paloscia S, Pettinato S, Santi E, et al (2013) Soil moisture mapping using Sentinel-1 images: Algorithm and preliminary validation. Remote Sensing of Environment 134:234-248. https://doi.org/10.1016/j.rse.2013.02.027

Parrens M, Al Bitar A, Frappart F, et al (2017) Mapping Dynamic Water Fraction under the Tropical Rain Forests of the Amazonian Basin from SMOS Brightness Temperatures. Water 9:350. https://doi.org/10.3390/w9050350

Parrens M, Bitar AA, Frappart F, et al (2019) High resolution mapping of inundation area in the Amazon basin from a combination of L-band passive microwave, optical and radar datasets. International Journal of Applied Earth Observation and Geoinformation 81:58-71. https://doi.org/10.1016/j.jag.2019.04.011 
Pedinotti V, Boone A, Ricci S, et al (2014) Assimilation of satellite data to optimize large-scale hydrological model parameters: a case study for the SWOT mission. Hydrology and Earth System Sciences 18:4485-4507. https://doi.org/10.5194/hess-18-4485-2014

Pekel J-F, Cottam A, Gorelick N, Belward AS (2016) High-resolution mapping of global surface water and its long-term changes. Nature 540:418-422. https://doi.org/10.1038/nature20584

Petiteville I, Ishida C, Danzeglocke J, et al (2015) WCDRR and the CEOS activites on disasters. International Archives of the Photogrammetry, Remote Sensing \& Spatial Information Sciences 76. https://doi.org/10.5194/isprsarchives-XL-7-W3-845-2015

Pettinari ML, Chuvieco E (2020) Fire Danger Observed from Space. Surv Geophys. https://doi.org/10.1007/s10712-020-09610-8

Pham HT, Marshall L, Johnson F, Sharma A (2018) Deriving daily water levels from satellite altimetry and land surface temperature for sparsely gauged catchments: A case study for the Mekong River. Remote Sensing of Environment 212:31-46. https://doi.org/10.1016/j.rse.2018.04.034

Prigent C, Papa F, Aires F, et al (2007) Global inundation dynamics inferred from multiple satellite observations, 1993-2000. Journal of Geophysical Research: Atmospheres 112:. https://doi.org/10.1029/2006JD007847

Reager J, Thomas A, Sproles E, et al (2015) Assimilation of GRACE Terrestrial Water Storage Observations into a Land Surface Model for the Assessment of Regional Flood Potential. Remote Sensing 7:14663-14679. https://doi.org/10.3390/rs71114663

Reager JT, Famiglietti JS (2009) Global terrestrial water storage capacity and flood potential using GRACE. Geophysical Research Letters 36:. https://doi.org/10.1029/2009GL040826

Reager JT, Thomas BF, Famiglietti JS (2014) River basin flood potential inferred using GRACE gravity observations at several months lead time. Nature Geoscience 7:588-592. https://doi.org/10.1038/ngeo2203

Reichle RHA (2018) Soil Moisture Active Passive (SMAP) Mission Level 4 Surface and Root Zone Soil Moisture (L4_SM) Product Specification Document

Richey AS, Thomas BF, Lo M-H, et al (2015) Uncertainty in global groundwater storage estimates in a Total Groundwater Stress framework. Water Resources Research 51:5198-5216. https://doi.org/10.1002/2015WR017351

Robinson DA, Campbell CS, Hopmans JW, et al (2008) Soil Moisture Measurement for Ecological and Hydrological Watershed-Scale Observatories: A Review. Vadose Zone Journal 7:358-389. https://doi.org/10.2136/vzj2007.0143

Rodell M (2012) Satellite Gravimetry Applied to Drought Monitoring. Remote Sensing of Drought: Innovative Monitoring Approaches 261. https://doi.org/10.1201/b11863-18

Rodríguez-Fernández NJ, Anterrieu E, Rougé B, et al (2019) SMOS-HR: A High Resolution L-Band Passive Radiometer for Earth Science and Applications. IGARSS 2019 - 2019 IEEE International Geoscience and Remote Sensing Symposium. https://doi.org/10.1109/IGARSS.2019.8897815

Santos da Silva J, Calmant S, Seyler F, et al (2010) Water levels in the Amazon basin derived from the ERS 2 and ENVISAT radar altimetry missions. Remote Sensing of Environment 114:2160 2181. https://doi.org/10.1016/j.rse.2010.04.020 
Schneider R, Godiksen PN, Villadsen H, et al (2017) Application of CryoSat-2 altimetry data for river analysis and modelling. Hydrology and Earth System Sciences 21:751-764. https://doi.org/10.5194/hess-21-751-2017

Schroeder R, McDonald KC, Chapman BD, et al (2015) Development and Evaluation of a Multi-Year Fractional Surface Water Data Set Derived from Active/Passive Microwave Remote Sensing Data. Remote Sensing 7:16688-16732. https://doi.org/10.3390/rs71215843

Schumann G, Di Baldassarre G, Alsdorf D, Bates PD (2010) Near real-time flood wave approximation on large rivers from space: Application to the River Po, Italy. Water Resources Research 46:. https://doi.org/10.1029/2008WR007672

Seitz F, Schmidt M, Shum CK (2008) Signals of extreme weather conditions in Central Europe in GRACE 4-D hydrological mass variations. Earth and Planetary Science Letters 268:165-170. https://doi.org/10.1016/j.epsl.2008.01.001

Siderius C, Gannon KE, Ndiyoi M, et al (2018) Hydrological Response and Complex Impact Pathways of the 2015/2016 El Niño in Eastern and Southern Africa. Earth's Future 6:2-22. https://doi.org/10.1002/2017EF000680

Soldo Y, Khazaal A, Cabot F, Kerr YH (2016) An RFI Index to Quantify the Contamination of SMOS Data by Radio-Frequency Interference. IEEE Journal of Selected Topics in Applied Earth Observations and Remote 9:1577-1589. https://doi.org/10.1109/JSTARS.2015.2425542

Stocker TF, Qin D, Plattner G-K, et al (2013) IPCC, 2013: Climate change 2013: The physical science basis. Contribution of Working Group I to the Fifth Assessment Report of the Intergovernmental Panel on Climate Change. Cambridge University Press, Cambridge, United Kingdom and New York, NY, USA

Stöckli R, Vermote E, Saleous N, et al (2005) Blue Marble Next Generation - A true color earth dataset including seasonal dynamics from MODIS. In: NASA Earth Observatory. https://earthobservatory.nasa.gov/features/BlueMarble. Accessed 29 Jan 2020

Sun Z, Zhu X, Pan Y, Zhang J (2017) Assessing Terrestrial Water Storage and Flood Potential Using GRACE Data in the Yangtze River Basin, China. Remote Sensing 9:1011. https://doi.org/10.3390/rs9101011

Svoboda M, Hayes M, Wood D (2012) Standardized precipitation index user guide. World Meteorological Organization Geneva, Switzerland

Swain S, Wardlow BD, Narumalani S, et al (2013) Relationships between vegetation indices and root zone soil moisture under maize and soybean canopies in the US Corn Belt: a comparative study using a close-range sensing approach. International Journal of Remote Sensing 34:2814-2828. https://doi.org/10.1080/01431161.2012.750020

Tapley BD, Bettadpur S, Ries JC, et al (2004) GRACE Measurements of Mass Variability in the Earth System. Science 305:503-505. https://doi.org/10.1126/science.1099192

Tarpanelli A, Amarnath G, Brocca L, et al (2017) Discharge estimation and forecasting by MODIS and altimetry data in Niger-Benue River. Remote Sensing of Environment 195:96-106. https://doi.org/10.1016/j.rse.2017.04.015

Tarpanelli A, Brocca L, Barbetta S, et al (2015) Coupling MODIS and Radar Altimetry Data for Discharge Estimation in Poorly Gauged River Basins. IEEE Journal of Selected Topics in 
Applied Earth Observations and Remote Sensing 8:141-148. https://doi.org/10.1109/JSTARS.2014.2320582

Tarpanelli A, Santi E, Tourian MJ, et al (2019) Daily River Discharge Estimates by Merging Satellite Optical Sensors and Radar Altimetry Through Artificial Neural Network. IEEE Transactions on Geoscience and Remote Sensing 57:329-341. https://doi.org/10.1109/TGRS.2018.2854625

Thomas AC, Reager JT, Famiglietti JS, Rodell M (2014) A GRACE-based water storage deficit approach for hydrological drought characterization. Geophysical Research Letters 41:15371545. https://doi.org/10.1002/2014GL059323

Thomas BF, Famiglietti JS, Landerer FW, et al (2017) GRACE Groundwater Drought Index: Evaluation of California Central Valley groundwater drought. Remote Sensing of Environment 198:384392. https://doi.org/10.1016/j.rse.2017.06.026

Tomer SK, Al Bitar A, Sekhar M, et al (2015) Retrieval and Multi-scale Validation of Soil Moisture from Multi-temporal SAR Data in a Semi-Arid Tropical Region. Remote Sensing 7:8128-8153. https://doi.org/10.3390/rs70608128

Tomer SK, Al Bitar A, Sekhar M, et al (2016) MAPSM: A Spatio-Temporal Algorithm for Merging Soil Moisture from Active and Passive Microwave Remote Sensing. Remote Sensing 8:990. https://doi.org/10.3390/rs8120990

Tourian MJ, Schwatke C, Sneeuw N (2017) River discharge estimation at daily resolution from satellite altimetry over an entire river basin. Journal of Hydrology 546:230-247. https://doi.org/10.1016/j.jhydrol.2017.01.009

Tourian MJ, Tarpanelli A, Elmi O, et al (2016) Spatiotemporal densification of river water level time series by multimission satellite altimetry. Water Resources Research 52:1140-1159. https://doi.org/10.1002/2015WR017654

Tralli DM, Blom RG, Zlotnicki V, et al (2005) Satellite remote sensing of earthquake, volcano, flood, landslide and coastal inundation hazards. ISPRS Journal of Photogrammetry and Remote Sensing 59:185-198. https://doi.org/10.1016/j.isprsjprs.2005.02.002

Twele A, Cao W, Plank S, Martinis S (2016) Sentinel-1-based flood mapping: a fully automated processing chain. International Journal of Remote Sensing 37:2990-3004. https://doi.org/10.1080/01431161.2016.1192304

Ulaby FTM (1981) Microwave remote sensing: Active and passive. Volume 1 - Microwave remote sensing fundamentals and radiometry

Wagner W, Hahn S, Kidd R, et al (2013) The ASCAT Soil Moisture Product: A Review of its Specifications, Validation Results, and Emerging Applications. Meteorologische Zeitschrift 22:5-33. https://doi.org/10.1127/0941-2948/2013/0399

Ward PJ, Jongman B, Kummu M, et al (2014) Strong influence of El Nino Southern Oscillation on flood risk around the world. Proceedings of the National Academy of Sciences 111:15659-15664. https://doi.org/10.1073/pnas.1409822111

Wilhite DA (2000) Drought as a Natural Hazard: Concepts and Definitions. 22

WMO (2012) International Glossary of Hydrology, UNESCO

World Resources Institute (2019) Aqueduct Floods. In: Aqueduct Floods. https://www.wri.org/applications/aqueduct/floods/. Accessed 28 Jul 2020 
Yamazaki D, Watanabe S, Hirabayashi Y (2018) Global Flood Risk Modeling and Projections of Climate Change Impacts. Global Flood Hazard: applications in modeling, mapping, and forecasting 233:254. https://doi.org/10.1002/9781119217886.ch11

Yang Y, Lin P, Fisher CK, et al (2019) Enhancing SWOT discharge assimilation through spatiotemporal correlations. Remote Sensing of Environment 234:111450. https://doi.org/10.1016/j.rse.2019.111450

Yoon Y, Beighley E, Lee H, et al (2016) Estimating Flood Discharges in Reservoir-Regulated River Basins by Integrating Synthetic SWOT Satellite Observations and Hydrologic Modeling. Journal of Hydrologic Engineering 21:05015030. https://doi.org/10.1061/(ASCE)HE.19435584.0001320

Yoon Y, Durand M, Merry CJ, et al (2012) Estimating river bathymetry from data assimilation of synthetic SWOT measurements. Journal of Hydrology 464-465:363-375. https://doi.org/10.1016/j.jhydrol.2012.07.028

Yu X, Moraetis D, Nikolaidis NP, et al (2019) A coupled surface-subsurface hydrologic model to assess groundwater flood risk spatially and temporally. Environmental Modelling \& Software 114:129-139. https://doi.org/10.1016/j.envsoft.2019.01.008

Zhang A, Jia G (2013) Monitoring meteorological drought in semiarid regions using multi-sensor microwave remote sensing data. Remote Sensing of Environment 134:12-23. https://doi.org/10.1016/j.rse.2013.02.023

Zhang D, Zhang Q, Werner AD, Liu X (2016) GRACE-Based Hydrological Drought Evaluation of the Yangtze River Basin, China. J Hydrometeor 17:811-828. https://doi.org/10.1175/JHM-D-150084.1

Zhao L, Dong H, Edelmann RE, et al (2017) Coupling of Fe(II) oxidation in illite with nitrate reduction and its role in clay mineral transformation. Geochimica et Cosmochimica Acta 200:353-366. https://doi.org/10.1016/j.gca.2017.01.004

Zhou H, Luo Z, Tangdamrongsub N, et al (2017) Characterizing Drought and Flood Events over the Yangtze River Basin Using the HUST-Grace2016 Solution and Ancillary Data. Remote Sensing 9:1100. https://doi.org/10.3390/rs9111100 